\title{
Numerical modeling of groin impact on nearshore hydrodynamics
}

\author{
M.V.L. Rocha ${ }^{\mathrm{a}, \mathrm{c}, *}$, C. Coelho ${ }^{\mathrm{b}}$, C.J.E.M. Fortes ${ }^{\mathrm{c}}$ \\ aveiro University, Physics Department and CESAM, Portugal \\ ${ }^{\mathrm{b}}$ Aveiro University, Civil Engineering Department and CESAM, Portugal \\ c LNEC National Civil Engineering Laboratory, Hydraulics and Environment Department, Portugal
}

\section{A R T I C L E I N F O}

Article history:

Received 19 January 2012

Accepted 18 March 2013

\section{Keywords:}

Nearshore hydrodynamics

Numerical modeling

COULWAVE

Groins

\begin{abstract}
A B S T R A C T
Groins are cross shore structures built to promote shoreline stabilization. However, the specific impact of these structures on the wave conditions and velocity field nearshore (and hence, on sediment transport) is still poorly understood. Therefore, this study wishes to extend this knowledge using a numerical model, COULWAVE, previously validated with field data. For that, a typical bar-trough profile is considered and different groin lengths and orientations are tested, under the influence of different significant incident-wave heights and sea-surface levels.

The hydrodynamics factors are found to have a greater impact on the nearshore wave conditions than the groin geometry. The variation of significant incident-wave height imparts the greater changes in wave height nearshore, where the groin would be located. The typical tidal range is also important, since a $2 \mathrm{~m}$ change in sea surface level can cause great depth changes over bathymetric features and thus influence wave propagation. Although less important, the geometry of the groin should also be considered. The greater the length, the greater the sheltering effect expected, extending further to the lee-side of the groin. The impact will also reach a broader region. With a smaller impact verified, the best orientation of the groin is hard to unravel.
\end{abstract}

(c) 2013 Elsevier Ltd. All rights reserved.

\section{Introduction}

Groins are cross-shore structures projected to retain sediments from the longshore drift, to attenuate the erosion of specific coastline stretches. The shoreline adjusts to the presence of the obstruction in longshore sediment transport, and after some time, accretion causes a positive increase in beach width updrift of the groin. Conservation of sand mass then produces erosion and decrease in beach width on the downdrift side of the groin (Basco, 2006). This morphodynamics is intrinsically associated with the specific hydrodynamics of the construction site.

The real impact and dependence of groins on the wave conditions and the velocity field nearshore is still an ongoing field of investigation and thus requires further research. Several authors have been pursuing this aim. Initially, authors like Bowen and Inman (1969) and Dean (1978) started understanding wave diffraction and current patterns on the lee-side of groins. Also the US Army Corps of Engineers (1992) has made thorough studies, namely about wave heights, tide levels and groin geometries and materials,

\footnotetext{
* Corresponding author at: Aveiro University, Physics Department and CESAM, Portugal, Tel.: +351 234378 100; fax: +351234378 197.

E-mail addresses: m.rocha@ua.pt (M.V.L. Rocha), ccoelho@ua.pt (C. Coelho), jfortes@lnec.pt (C.J.E.M. Fortes).
}

from an engineering perspective, to allow for those structures to be build the best way possible.

The direction of incident waves is also of particular importance in these kind of studies, as the waves arriving and breaking with different angles relatively to the beach, will tend to induce offshore-directed currents (rip-currents) near the lee-side of the groin. In this current, sediments are transported offshore and may become, at least partly and locally, lost from the nearshore system (Silvester and Hsu, 1993; Hanson and Larson, 2004). More recently, authors such as Pattiaratchi et al. (2009) have studied the nearshore current system resulting from the presence of a groin, using surf-zone drifters.

Prediction of the three-dimensional behavior of the beach volume near coastal structures, such as groins, requires sophistication in the operation of numerical simulation models that may not always be realistic for the site, budget or scale of the project (Basco and Pope, 2004). Furthermore, a precise evaluation of the impact and dependence of different groins on hydrodynamics is still to be attained. Hence, and to bring further insight on this matter, this work presents a numerical modeling study of groin impact on significant wave height and horizontal velocity nearshore, accounting for different incident wave heights and sea-surface levels and considering groins of different lengths and orientations relatively to the coast.

To attain this aim, the COULWAVE model (Lynett and Liu, 2002a, 2002b) is applied to a typical bar-trough profile beach 
(Costa da Caparica, western Portuguese coast), and forced with different incident wave-height conditions $(H s=1.0 \mathrm{~m}, H s=1.5 \mathrm{~m}$, $H s=2.0 \mathrm{~m}$ and $H s=3.0 \mathrm{~m}$ ) and sea-surface levels $(\mathrm{SSL}=0.50 \mathrm{~m}$, $\mathrm{SSL}=0.75 \mathrm{~m}, \mathrm{SSL}=1.50 \mathrm{~m}$ and $\mathrm{SSL}=2.40 \mathrm{~m}$ ). The bathymetry of the domain was altered to include groins of different lengths ( $L=200 \mathrm{~m}, L=250 \mathrm{~m}, L=300 \mathrm{~m}$ and $L=400 \mathrm{~m}$ ) and orientations $\left(\phi=10^{\circ}, \phi=15^{\circ}, \phi=25^{\circ}\right.$ and $\left.\phi=30^{\circ}\right)$.

\section{Numerical model-COULWAVE (Lynnet and Liu, 2004)}

\subsection{Model description}

COULWAVE (Cornell University Long and Intermediate Wave Modeling Package), a numerical model initially developed by Lynett and Liu (2002), based upon the extended Boussinesq-type equations deducted by Wei et al. (1995), allows for the evolution of fully-nonlinear and dispersive waves over variable bathymetry. The model equations are deducted from depth-integration of continuity and momentum equations, using a multi-layer concept, which considers the division of the water column in layers, each with a determined vertical velocity profile. The accuracy of the model is thus dependent on the number of layers considered and its applicability extends to very deep waters, as it continues to present linear characteristics up to $k h \sim 8$ and a second order nonlinear behavior up to $k h \sim 6$ (where $k$ is the wave number and $h$, the water depth).

In this work, the water column will be represented through one layer. Therefore, the horizontal velocity vector is calculated for a defined depth $z_{1}$ (herein $z_{1}=-0.531 h$, where $h$ is the water depth, recommended by Nwogu (1993) and adopted by most researchers).

For the numerical exterior boundaries two types of conditions are applied: reflection and radiation. The reflective, or no-flux boundary condition, follows the work of Wei and Kirby (1995) and for the radiation, or open boundary condition, a sponge layer is applied, in the manner recommended by Kirby et al. (1998).

Lynnet and Liu (2004) further introduced additional terms in the equations in order to account for bottom friction, wave breaking and wave generation inside the domain and added time-dependent water-depth terms, in order to consider bottomprofile time variations induced by landslides and earthquakes.

Bottom friction $\left(R_{f}\right)$ and wave breaking $\left(\vec{R}_{b}\right)$ are the two forms of physical dissipation considered. Since wave breaking is the most relevant physical dissipation phenomenon in this work, it is below explained in further detail.

The breaking scheme employed by Lynnet and Liu (2002) follows the work of Kennedy et al. (2000) and Chen et al. (2000), and is developed from an "eddy viscosity" approach, where a user-defined formulation for eddy viscosity is part of a momentum conserving, ad hoc, dissipative term, $\vec{R}_{b}$, with components $R_{b x}$ and $R_{b y}$ as it follows:

$R_{b x}=\frac{1}{H}\left\{\left[\nu\left(H u_{1}\right)_{x}\right]_{x}+\frac{1}{2}\left[\nu\left(H u_{1}\right)_{y}+\nu\left(H v_{1}\right)_{x}\right]_{y}\right\}$

$R_{b y}=\frac{1}{H}\left\{\left[\nu\left(H v_{1}\right)_{y}\right]_{y}+\frac{1}{2}\left[\nu\left(H v_{1}\right)_{x}+\nu\left(H u_{1}\right)_{y}\right]_{x}\right\}$

where indexes $x$ and $y$ represent the spatial derivatives, $H=h+\zeta$ is the total water depth, and $\nu$ is the eddy viscosity, given by:

$\nu=B H \zeta_{t}$

The purpose of $B$ is to ensure a smooth transition between breaking and non-breaking states and it can be defined, following
Kennedy et al. (2000), by:

$B=\left\{\begin{array}{cc}\delta, & \zeta_{t} \geq 2 \zeta_{t}^{b} \\ \delta\left(\zeta_{t} / \zeta_{t}^{b}-1\right), & \zeta_{t}^{b}<\zeta_{t} \leq 2 \zeta_{t}^{b} \\ 0, & \zeta_{t} \leq \zeta_{t}^{b}\end{array}\right\}$

where $\delta$ is an amplification factor and the parameter $\zeta_{t}^{b}$ determines the onset and cessation of wave breaking and is defined by:

$\zeta_{t}^{b}=\left\{\begin{array}{cc}\zeta_{t}^{(F)}, & t-t_{o} \geq T^{b} \\ \zeta_{t}^{(I)}+\frac{t-t_{o}}{T^{b}}\left(\zeta_{t}^{(F)},-\zeta_{t}^{(I)}\right), & 0 \leq t-t_{o}<T^{b}\end{array}\right\} ;$

where $\zeta_{t}^{(I)}$ is the initial free-surface transient threshold that must be exceeded for a breaking event to initiate, $\zeta_{t}^{(F)}$ is the minimum transient required for a breaking event to continue, $t$ is the local time instant, $t_{o}$ is the time instant when breaking started, and $T^{b}$ is a transition time.

From this point, the breaking model by Lynett and Liu (2002) diverges from the one formulated by Kennedy et al. (2000), that described the four free breaking parameters based on the linear long-wave speed (i.e. $\zeta_{t}^{(I)}=0.65 \sqrt{g h}$ ), and a description based on the nonlinear long-wave speed $(\sqrt{g H})$ is chosen instead, to avoid problems with calculations where $h<0$ (as when a wave runs up the shoreline). A number of regular wave tests on plane slopes performed by Hansen and Svendsen (1979) allowed the default setting of the free parameters to be defined as:

$\delta=6.5, \quad \zeta_{t}^{(I)}=0.65 \sqrt{g H}, \quad \zeta_{t}^{(F)}=0.08 \sqrt{g H}, \quad T^{b}=8.0 \sqrt{\frac{H}{g}}$

The values of these parameters were defined for smooth plane slopes and should hence be adjusted if bottom profile conditions are different.

\subsection{Model validation}

Before introducing a groin in the simulation domain, an evaluation of the model performance for the specific field site to be simulated was made, using field data previously collected in Praia da Cornélia, Costa da Caparica (Portugal), during a field campaign carried out in the scope of a FCT (Fundação para a Ciência e Tecnologia) financed project, BRISA (Breaking Waves and Induced Sand Transport), described in Rocha (2011).

The in situ data collected in the field campaign that are analyzed in this work, consist on simultaneous measurements of pressure and horizontal current velocity, acquired with instruments (pressure transducers, PT, and an electromagnetic current meter, ECM) approximately located along the same cross-shore profile, attached to H-shaped structures (Fig. 1).

Free-surface measurements from three pressure transducers are analyzed: one positioned in deeper waters, PT00, $(7.6 \mathrm{~m}$, referred to $\mathrm{CD}$ ) and two located closer to the shore (PT01 and PT02), in the surf zone. Horizontal velocity was measured along both cross-shore and longshore directions, using the ECM located in the surf zone.

Simulations were then run with COULWAVE model and significant wave height and period values simulated were compared with field data for all the four sensors, and the performance of the model was evaluated through BIAS, RMSE and Agreement Index scores. Further, a spectral analysis with Fourier and Wavelet methods was carried out for the free-surface elevation time series, allowing the investigation of the ability of the model to simulate nonlinear characteristics of the waves, as they propagate towards the shore, evidencing both the energy-density distribution by frequencies (Fourier method) and the frequency distribution of the energy along the measuring time period (Wavelet method). 
a

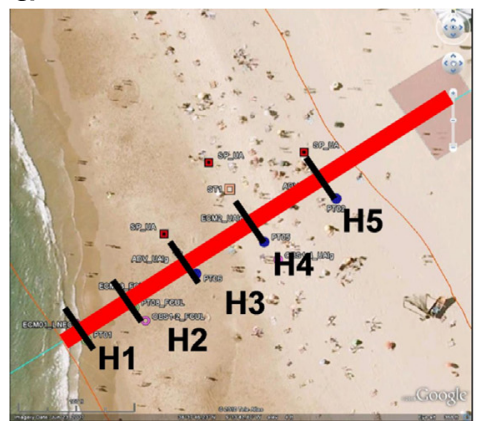

b

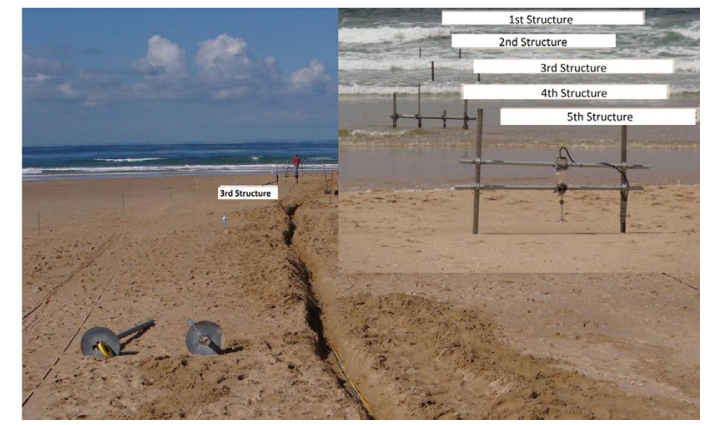

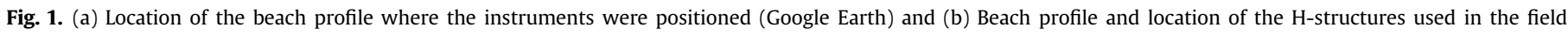
campaign (Bezerra and Ferreira, 2010).
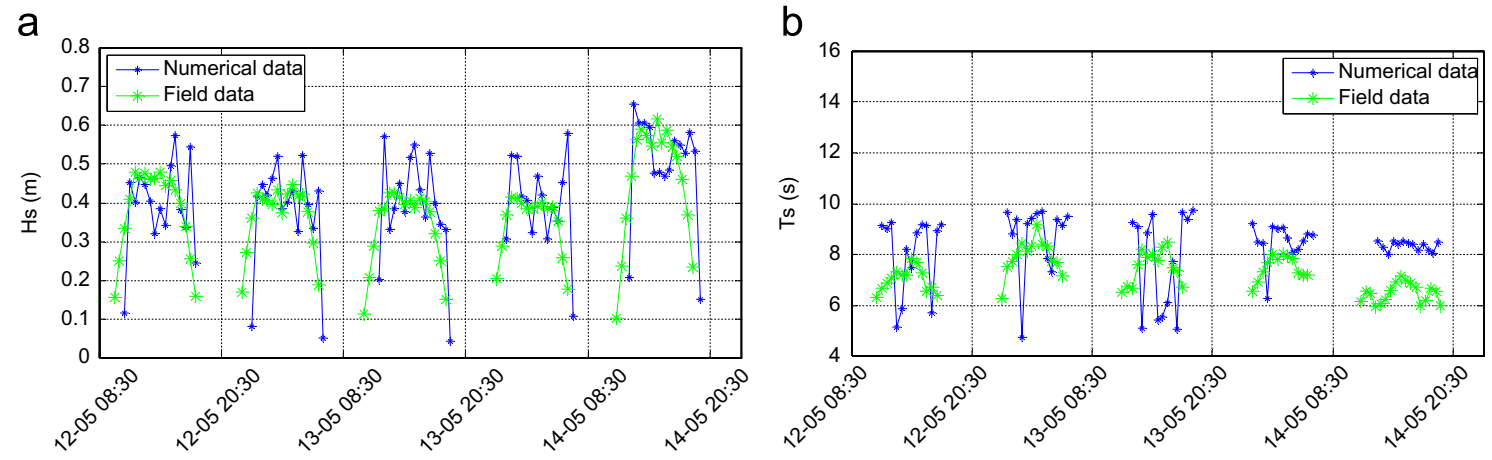

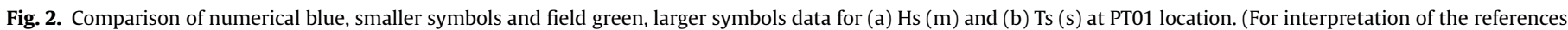
to color in this figure legend, the reader is referred to the web version of this article.)

Fig. 2a and $\mathrm{b}$ shows an example of $\mathrm{Hs}$ and Ts comparison between model results and field data, for PT01 sensor. Figs. 3 and 4a and b depict, still for the same location, the comparison of field data and numerical results of the energy spectra obtained both with Fourier and Wavelet methods. Fig. 5 presents an example of the comparison of measured and simulated values of velocity, in this case, the cross-shore component only (maximum, minimum, mean and root-mean-square). Tables 1-4 show the values of the model performance indexes, for all the four parameters considered (Hs, Ts, cross-shore and longshore velocity components, respectively).

From a general perspective, the model is able of simulating the trends and orders of magnitude of the field data, particularly for Hs values. For Ts values, the absolute differences are greater.

Being the input time series, the free-surface elevation measured in PT00 is quite accurately simulated. For PT01 instrument positions, the numerical results obtained are quite promising, which points out the ability of the model to simulate wave propagation towards the shore, particularly before wave breaking. For locations higher up the beach profile (such as PT02), where the waves are expected to be already broken, the model reveals a greater difficulty in simulating field data.

The differences between numerical and field data can be a consequence of:

- The directions of numerical incident waves being always considered perpendicular to the coast (which aggravates wave conditions in the sensors near the shoreline), and not corresponding to the real directions of the waves that effectively arrived to shore in Cornélia beach, during the period of the campaign. This limitation was mostly an unavoidable consequence of the fact that the wave direction was not measured during the campaign.

- Limitations inherent to the model; particularly, it is important to underline that the application of the model to bottom slopes

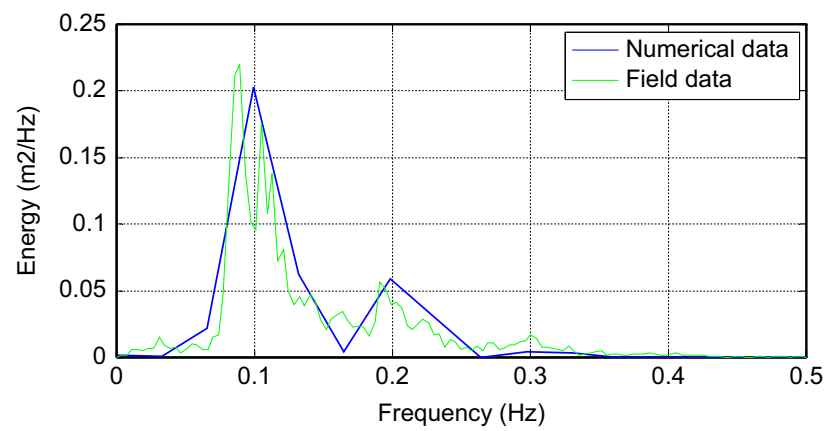

Fig. 3. Fourier energy spectra $\left(\mathrm{m}^{2} \mathrm{~Hz}^{-1}\right)$ field data versus numerical results in PT01 location. The chosen 30-min interval starts at 3:00 on the 13-05-2010.

of about $1 / 6$ can be critical, since its fundamental equations are integrated assuming mild-sloping bottoms. Furthermore, phenomena such as wave breaking are included in the model through the addition to the original equations of a turbulent viscosity term, which depends on a set of parameters related to the onset, duration and cessation of breaking events that should be calibrated for each single case study and wave condition imposed. These parameters, herein considered constant for all the 127 different incident wave conditions, should, for greater accuracy, be individually calibrated.

On the spectral domain, for both PT01 and PT02, the model identifies the main range of periods present and represents relatively well the presence of higher frequencies $(0.2 \mathrm{~Hz})$, for PT01, and lower-frequencies $(0.05 \mathrm{~Hz})$ for PT02, with less associated energy. However, the model is still limited on the simulation of energy dispersion to higher and lower frequencies than the higher-energy frequencies, which acquires a particular relevance for the instruments closer to the shore. It is also important to note 
a

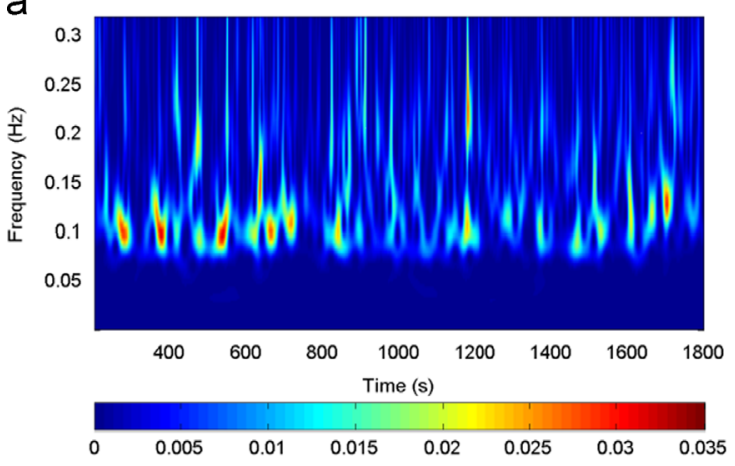

b

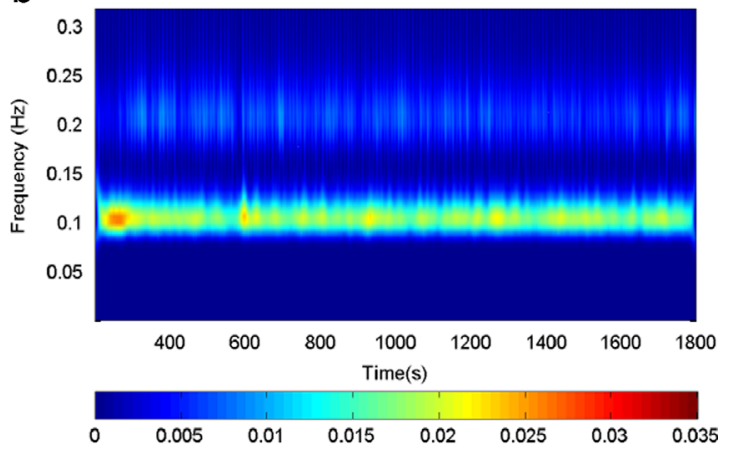

Fig. 4. Wavelet energy spectra $\left(\mathrm{m}^{2} \mathrm{~Hz}^{-1}\right)$ of (a) field data versus (b) numerical results for PT01 locations. The chosen 30-min interval starts at 3:00 on the 13-05-2010.

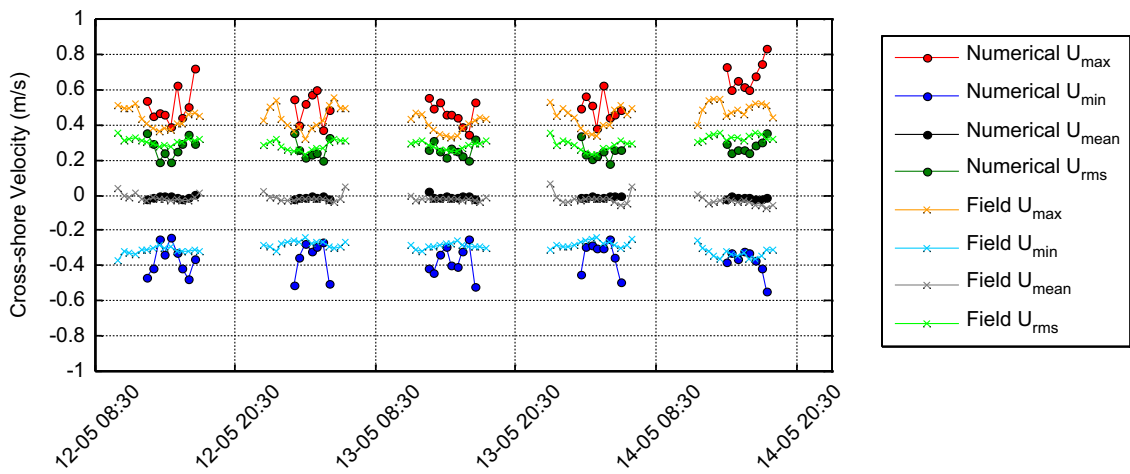

Fig. 5. Comparison of numerical (dots) and field (crosses) maximum, minimum, mean and root-mean-square velocities (ms $\left.{ }^{-1}\right)$ of the cross-shore $(U)$ component.

Table 1

Values of BIAS, RMSE and $d$ calculated for Hs values, in PT00, PT01 and PT02 locations.

\begin{tabular}{llll}
\hline Instrument & BIAS $(\mathrm{m})$ & RMSE $(\mathrm{m})$ & $d$ \\
\hline PT00 & 0.007 & 0.009 & 1.00 \\
PT01 & 0.023 & 0.126 & 0.93 \\
PT02 & 0.126 & 0.105 & 0.84 \\
\hline
\end{tabular}

Table 2

Values of BIAS, RMSE and $d$ calculated for Ts values, in PT00, PT01 and PT02 locations.

\begin{tabular}{llll}
\hline Instrument & BIAS $(\mathrm{s})$ & RMSE $(\mathrm{s})$ & $d$ \\
\hline PT00 & -0.006 & 0.025 & 1.00 \\
PT01 & 0.912 & 1.891 & 0.93 \\
PT02 & - & - & - \\
\hline
\end{tabular}

Table 3

Values of BIAS, RMSE and $d$ calculated for maximum, minimum, mean and rootmean-square values of the $U$ component.

\begin{tabular}{llll}
\hline Velocity & BIAS $\left(\mathrm{ms}^{-1}\right)$ & RMSE $\left(\mathrm{ms}^{-1}\right)$ & $d$ \\
\hline Umax & 0.186 & 0.322 & 0.51 \\
Umin & -0.119 & 0.169 & 0.49 \\
Um & 0.010 & 0.036 & 0.71 \\
Urms & 0.006 & 0.085 & 0.94 \\
\hline
\end{tabular}

that the model was forced with monochromatic waves, and hence a dispersion of the energy to multiple frequencies is less expected than it is for field data, which is originated by irregular wave spectra.
Table 4

Values of BIAS, RMSE and $d$ calculated for maximum, minimum, mean and rootmean-square values of the $V$ component.

\begin{tabular}{lclc}
\hline Velocity & BIAS $\left(\mathrm{ms}^{-1}\right)$ & RMSE $\left(\mathrm{ms}^{-1}\right)$ & $d$ \\
\hline Vmax & -0.037 & 0.055 & 0.90 \\
$V \mathrm{~min}$ & 0.057 & 0.072 & 0.88 \\
$V \mathrm{~m}$ & 0.072 & 0.083 & 0.73 \\
$V \mathrm{rms}$ & -0.079 & 0.097 & 0.84 \\
\hline
\end{tabular}

Comparing numerical and field data values of cross-shore and longshore components of the velocity, it is evident that:

- For both U and V components, the BIAS and RMSE values close to zero point to a good model performance in the simulation of velocity for PT01 location. It is however clear the greater difficulty of the model to conveniently simulate the conditions observed during the 30-min intervals of the last tidal cycle, particularly for the $V$ component, in which an excessive deviation between measured and simulated data is noticeable.

- The order of magnitude of field data is well represented, but the model seems less able to describe the general trend. Numerical data (maximum, minimum, mean and root mean square velocities) show greater oscillation between consecutive 30-min intervals than field data, which justifies the relatively low values of the agreement index.

- The over- and under-estimation of, respectively, $U$ and $V$ field data, are most likely related to the wave propagation direction: the model was forced with perpendicular wave directions to the coast, which induces greater values of $U$, and smaller values of $V$, contrariwise to the real direction of propagation in the field, where the obliquity of the waves propagating to shore will tend to result in a weaker-than-simulated $U$ component and stronger-than-simulated $V$ component. 


\subsection{Simulation conditions}

The incident wave conditions simulated for the initial runs aiming model validation corresponded to regular waves with characteristics based on the values measured by PTO0 sensor in the Cornélia beach, during the measuring period, between the 12th and the 14th of May, 2010. A perpendicular direction of incident waves was assumed, since the instruments on the field could not register wave direction and thus this parameter cannot be validated.

For each incident wave condition, defined by its significant wave height and period, sea-surface level and water depth, the model was run during $300 \mathrm{~s}$ (except for the case of spectral analysis, where it was run during $1800 \mathrm{~s}$ ), and the results were written to file every $1.0 \mathrm{~s}$. Computational and time expenses made it prohibitive running all the simulations much longer. It is assumed that even though the duration of the runs was quite short, it was enough for avoiding the effects of the selected initial conditions.

The bathymetry considered to construct the model grid corresponded to a discretization of the real bathymetry surveyed during the field campaign (Fig. 6). Hence, the bathymetry grid, with $900 \mathrm{~m}$ along the $x$-direction and $858 \mathrm{~m}$ along the $y$-direction, was defined by a cell size equal to $2 \mathrm{~m}$ in both directions. Based on that bathymetry grid, the computational grid was created by the numerical model based on a minimum number of points per wavelength, set as 30 in the simulations performed, defined according to the wave period.

It was further added a constant-depth zone to the domain, where the referred incident regular waves were generated through the source-function method (Wei et al., 1995). The source-function was located in the position $x=100 \mathrm{~m}$. In both left and right open boundaries of the domain, absorption boundary conditions were applied $\left(l_{0} / 2=\left(g T^{2}\right) / 4 \pi\right.$ layers, where $l_{0}$ is the wavelength, $T$ the wave period and $g$ the acceleration due to gravity), while the other two boundaries were considered reflective.

It was considered, for all simulations, only one layer, fullynonlinear equations (with nonlinear dispersive terms), a bottom friction coefficient of $1.0 \times 10^{-2}$ and a Courant number of 0.4 .

Considering $\zeta_{t}^{(I)}=A \sqrt{g H}$, the default value of $A$ set for a smoothplane sloping bottom profile is 0.65 . However, Chen et al. (2000) argued a value of 0.35 for bar-trough profile beaches, like the one considered in this study. Since diverse groins are to alter the bar-trough profile for each scenario to be studied, and after several attempts of parameter adjustment were made, a value of $A=0.50$ was assumed in this work, to allow for the greatest number of simulations to run without crashing and conveniently simulate the breaking events.

The values of the parameters not mentioned herein were set as the default values suggested by the manual of the model (Lynett and Liu (2002, 2004)).

\section{Simulation of groin impact}

\subsection{Introduction}

The model was then used to study groin impact on significant wave height and horizontal velocity near the shore. These hydrodynamic characteristics are of great importance for the evaluation of sediment transport patterns and consequent impacts on morphodynamics (loss of sediments seaward, cross-shore profileshapes updrift and downdrift of the groin, etc.). Different groin lengths and orientations relatively to the coast, and different incident wave heights and sea-surface levels were tested.

\subsubsection{The scenarios}

Several scenarios were considered, with the following characteristics:

- Variation of the groin length: $L=200 \mathrm{~m}, L=250 \mathrm{~m}, L=300 \mathrm{~m}$ and $L=400 \mathrm{~m}$

- Variation of the groin orientation: $\phi=10^{\circ}, \phi=15^{\circ}, \phi=25^{\circ}$ and $\phi=30^{\circ}$;

- Variation of the incident-waves significant height: $H s=1.0 \mathrm{~m}$, $H s=1.5 \mathrm{~m}, H s=2.0 \mathrm{~m}$ and $H s=3.0 \mathrm{~m}$;

- Variation of the sea-surface level: $\mathrm{SSL}=0.50 \mathrm{~m}, \mathrm{SSL}=0.75 \mathrm{~m}$, $\mathrm{SSL}=1.50 \mathrm{~m}$ and $\mathrm{SSL}=2.40 \mathrm{~m}$.

All the scenarios are compared with a so called controlscenario with a groin defined by $L=200 \mathrm{~m}$ and $\phi=10^{\circ}$ and considering the incident wave with $\mathrm{Hs}=1.0 \mathrm{~m}$ and $\mathrm{SSL}=0.50 \mathrm{~m}$.

The choice of scenarios intended to approach a wide range of possibilities often present in real situations and to analyze the influence of four of the most important parameters to be considered when a groin has to be built. However, it was also a

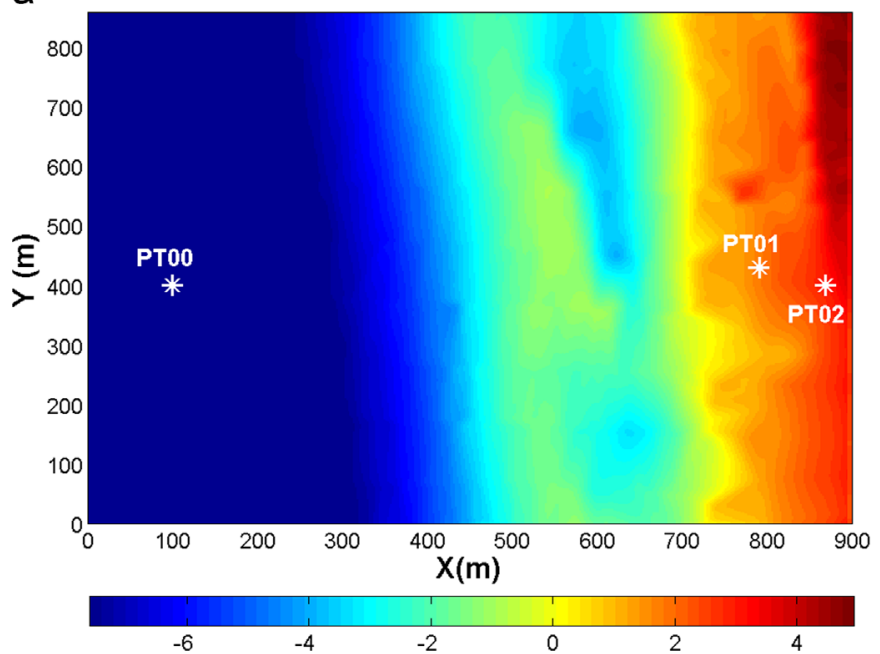

b

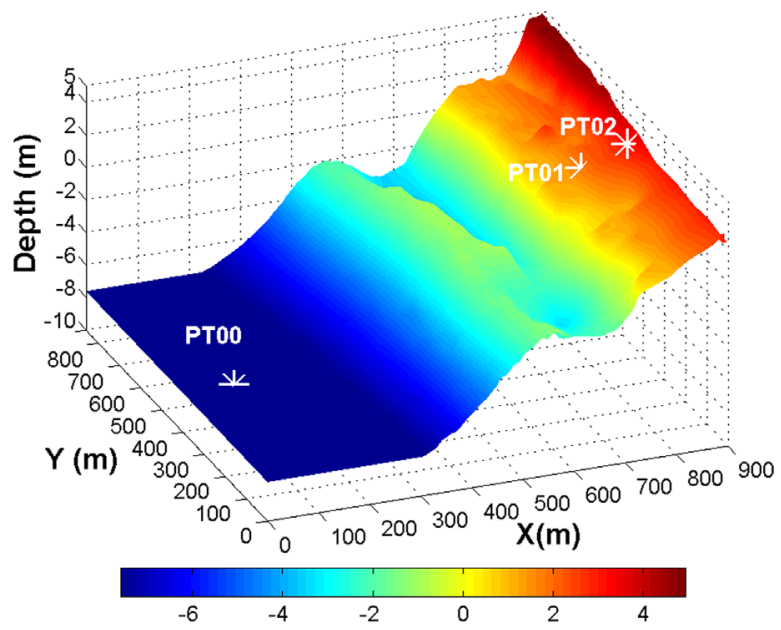

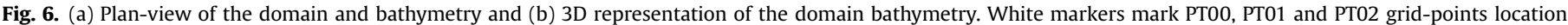
(respectively, from the most offshore location to the beach). These were the locations of the pressure transducers that acquired the data for model calibration. 
constrained by model limitations, such as the difficulty (or even impossibility) of the model to simulate scenarios where wave breaking would occur too close to the head of the groin. In such cases, the model would crash, most likely due to the abrupt change in bathymetry caused by the imposition of the groin to the original bathymetry of the domain. Wave heights, too high or too small, were also a problem for the model to simulate wave breaking events.

Morphodynamic changes were not considered (the bathymetry was kept constant for all scenarios, independently of hydrodynamic conditions), as evaluating these together with hydrodynamics would imply a great increase of the complexity of this study.

\subsubsection{The groins}

For each simulation, the landward groin end was positioned the furthest away possible from the reflective boundaries (approximately at $x=890 \mathrm{~m}$ and $y=440 \mathrm{~m}$, slightly changing for each scenario). Its length, L, was measured seawards from the shoreline, and its shoreward tip was extended to the right boundary of the domain. All the groins were designed to have a width, $\mathrm{W}$, of $6 \mathrm{~m}$ on the top, located $5 \mathrm{~m}$ above chart datum, h, and a side-slope of $1 / 2(\mathrm{~V} / \mathrm{H})$ (Fig. 7).

\subsubsection{The analysis}

Firstly, for each scenario, the significant wave height and the mean breaking locations (where at any instant of the 300-s run breaking occurred) across the domain were calculated for the entire domain. The domain color maps for these two variables are presented, mostly to help the subsequent analysis performed for the transects and to provide a general view of the different scenarios (view, for e.g., Fig. 10)

Afterwards, and for each grid point of the transects, the percentual relative difference between the considered scenario and the control scenario was calculated, and differences greater than a pre-established value (to be specified later, for each parameter $-5 \%, 7.5 \%$ or $10 \%$ ) were considered significant for the ensuing analysis. The value of the percentual difference defined for each parameter $(5 \%, 7.5 \%$ or $10 \%)$ was chosen to be the lower limit from below which the differences become too spread over the entire domain to have any significance. These limits were established, after a great set of tests with different values was performed in order to evaluate which thresholds would be most adequate for each parameter. The first lower limit, of $5 \%$, was chosen for a question of simplicity, and values were tested subsequently for increments of $2.5 \%$. These differences between each scenario and the control scenario were calculated for $\mathrm{Hs}$ and $U$ (Umax, Umin and Umean) and $V$ (Vmax, Vmin and Vmean) components of horizontal velocity, in the case of the control runs, and only Hs for the other runs.

The grid points along the transects where the differences were considered significant were evidenced in the domain (by black stretches - lines constituted by grid points marked in black - view Fig. 8 for schematic e.g.), and the extension (length) of these black stretches was calculated for each transect. From this, the total length of the stretches for all the 9 transects in each direction was determined.

Besides evaluating the length of stretches (where differences were considered significant), the absolute value of mean change was also evaluated (for e.g., view Fig. 10d and f). This mean change is a spatial-average, obtained for each transect, from the value of the Hs (or Umax, Umin, Umean, Vmax, Vmin, Vmean) difference between both scenarios, in each grid point of the transect.

The calculation of $\mathrm{Hs}$ implies a time-average of the highest $1 / 3$ of wave heights simulated by the model along the $300 \mathrm{~s}$ of simulation. Umean and Vmean are simple time-averages respectively of $U$ and $V$ components of the horizontal velocity, in each grid point, and will thus point out the mean direction of crossshore and longshore components. In turn, Umax and Umin and $V \max$ and $V$ min are the mean maximum and mean minimum values, respectively, and for each of the velocity components, registered during the total period of $300 \mathrm{~s}$. These mean of maxima and mean of minima are calculated considering a wave-by-wave analysis, using the zero-crossing method, with the threshold for minimum wave height set for $1 \%$ of the maximum wave height registered in the time series. The same methodology was applied for both $x$ - and $y$-directions transects.

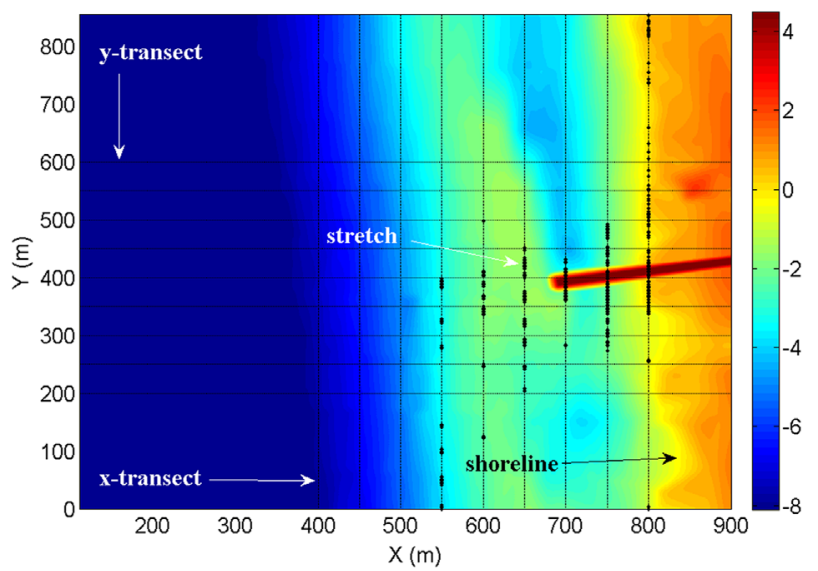

Fig. 8. Schematic representation of the transects and stretches mentioned in the analysis. The shoreline corresponds to the zero-depth color $(\mathrm{m})$. Positive values in the colorbar correspond to the height above zero, and negative values represent the depth below zero. a

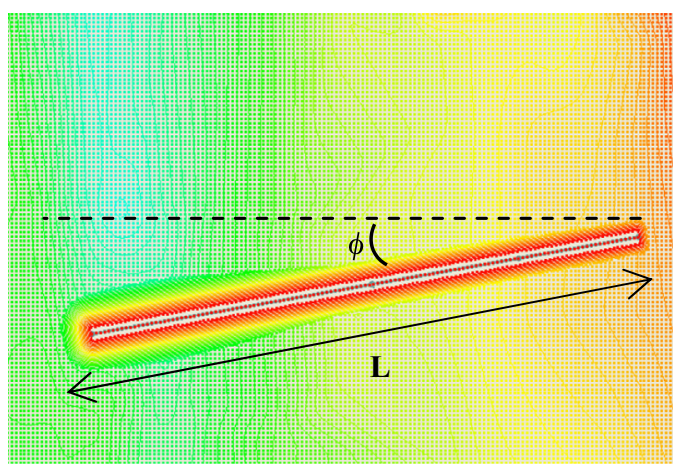

b

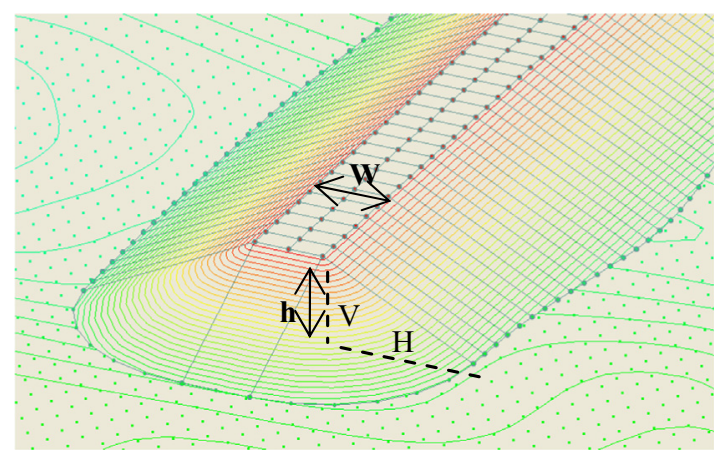

Fig. 7. Groin characteristics: (a) Length and orientation and (b) Height, width and side-slope. 
When observing the plots, some important issues should be considered:

- The domain output by the model does not match the exact domain considered: it was cropped along the $x$-direction, from the output domain for values of $x$ between 110 and $1010 \mathrm{~m}$. This was done in order to exclude from visualization the areas of the layer near the boundaries of the output domain, in both right and left sides. The extent of these boundary layers was observed to vary from one scenario to another, reaching variations of about $100 \mathrm{~m}$ or more, determined by the model. Nevertheless, and for simplification purposes, the extracted domain was for all scenarios considered the same.

- Together with the boundary layers, also the $x$ and $y$ positions and the spacing of the grid points varied from one scenario to another. Hence, for each scenario, the values of Hs (and velocities) had to be interpolated to a regular $900 \times 858 \mathrm{~m}$ grid (original dimensions of the domain input to the model), before the transects were defined, in order to establish a standard procedure and comparable data for analysis.

- Due to model limitations (such as its spatial resolution), some values of Hs (and velocities) were calculated for grid points which were above the sea-surface level. Hence, these values affect the calculations of the length of the stretches where differences were considered significant and consequently the mean change values, and are erroneously marked with black on the color maps. Despite the minor effect of these errors on the length of the black stretches and on mean change values, care must be taken when interpreting the color maps, in order to not consider the stretches of the transects above de sea-surface level.

- The values of mean difference along the transects represented in the mean change plots are absolute values and should thus be considered with care. For the percentual relative difference, the color maps should be analyzed. This is particularly relevant, for e.g., in the $x$-transects closer to the shoreline, since the waves there, already broken, have smaller Hs, and a smaller absolute Hs difference between scenarios, but eventually a greater relative difference.

- For a question of simplicity, the side of the groin closer to the upper boundary of the domain will be designated as its upper side or updrift side, and the side closer to the lower boundary will be called the lee-side or downdrift side.

\subsection{Control runs}

Firstly, and to understand the groin impact on a beach, two simulations were run:

- No Groin - The bathymetry of the domain did not include any groin, the incident significant wave height considered was $1.0 \mathrm{~m}$ and the sea-surface level was assumed to be $0.50 \mathrm{~m}$.

- Control Groin - A 200 m-long groin was added to the bathymetry of the domain, $10^{\circ}$ rotated to the downdrift of the shoreline-perpendicular. The incident wave and sea-surface level were considered the same as in the previous simulation.

The relative Hs and velocities differences between both runs were considered significant when greater than $10 \%$.

Fig. 9 presents the domain color maps of Hs (Fig. 9a and b) and wave breaking (Fig. 9c and d), for both no-groin and control-groin runs. The color bar present in the Hs color maps indicates the values of $\mathrm{Hs}(\mathrm{m})$. The brownish area represents land, i.e., the area of the domain that, during the $300 \mathrm{~s}$ of each simulation is, in average, above the sea-surface level. For the breaking color maps, the dark blue regions are regions where breaking never occurs during the $300 \mathrm{~s}$ of each run. Apart from the dark blue regions, the warmer the colors represented, the more frequently, averaging over the $300 \mathrm{~s}$, wave breaking occurs in those regions.

From Fig. 9, it is possible to verify that wave height increases near the head of the groin, and hence waves break adjacent to this point, towards the lee-side of the groin. The presence of the groin affects most of the domain, generating a diffraction effect and a shadow-zone close to shore, in the lee-side of the groin, where the waves are already broken and Hs is smaller. In the upper-side of the groin, reflection is the most important phenomenon.

Fig. 10a and b color maps represent the depth of the domain (the greater the depth, the more negative the values). In these figures, the grid points of the $x$ - and $y$-transects, respectively, where the percentual relative Hs differences between controlgroin and no-groin runs were greater than $10 \%$ were evidenced in the domain (marked with black stretches, and henceforth named stretches of Hs change).

Fig. 10c and e plots show the sum of all the grid points marked with black (total length of the various stretches, henceforth named length of groin impact), in each transect, in Fig. 10a and b, respectively. Fig. $10 \mathrm{~d}$ and $\mathrm{f}$ plots present the mean (along each transect) of the Hs difference (in each grid point of that transect) between control-groin and no-groin runs, for $x$ - and $y$-transects, respectively (henceforth named mean change). For these four figures, the continuous black lines marked along the $x=0$ (and $y=0$ ) axis represent, approximately, the positions along $x$ (and along $y$ ) that, at some point along $y$ (and $x$ ) are crossed by the groin. Analogously, for other scenarios, different lines with different dashes will represent the different groins, when necessary.

In the area further outside the tip of the groin, Hs increases, mostly near the head, and decreases in the inner (the groin) region (Fig. 10). This is a result of the bathymetry change imparted by the groin: near its head, the end-slope, extending downwards to the sea-bottom, provides a region of bathymetry shallower than the original. Also, in the shadow-zone of the structure, in its lee-side, the wave height diminishes. Although more transects account for a wave height increase, this change is less important and more localized in the vicinity of the groin, since it extends along shorter stretches of the transects than the wave height decrease, which affects a wider area of depths shallower than the head of the groin.

Figs. 11 and 12, respectively, present an analysis of $U$ and $V$ components of horizontal velocity, analogous to the analysis performed on Fig. 10, for Hs.

The presence of the groin results in greater significant wave heights and frequency of breaking events near its head, where before no breaking would occur. Associated with these events, there is an increase in the cross-shore velocity towards the shore, near the groin and in the breaking region, and an increase in the seaward direction, in regions further away from the groin, as the water must return offshore, after the wave breaking. Since the model simulates the velocity at mid-depth of the water column, without the groin, the most relevant cross-shore velocity close to shore is a weak undertow, so usually $U$ is most frequently directed offshore than towards the coast, although higher absolute values are registered in the direction of the coast, most likely associated with wave breaking events. The groin introduces in the domain more regions where breaking events are most relevant, particularly near its tip, and hence cross-shore velocity towards the coast increases in this region, and further away the weak undertow, directed offshore, persists (Fig. 13). In areas where no breaking events happen, since the model only simulates the velocity field associated with the propagation of the waves (which were input to the model propagating perpendicularly to the shore), mean velocity is almost zero, as the water particles oscillate back and forth as the waves pass by.

Since the waves propagate perpendicularly to the shore, the initial velocity field is mostly along the cross-shore direction. The 
a

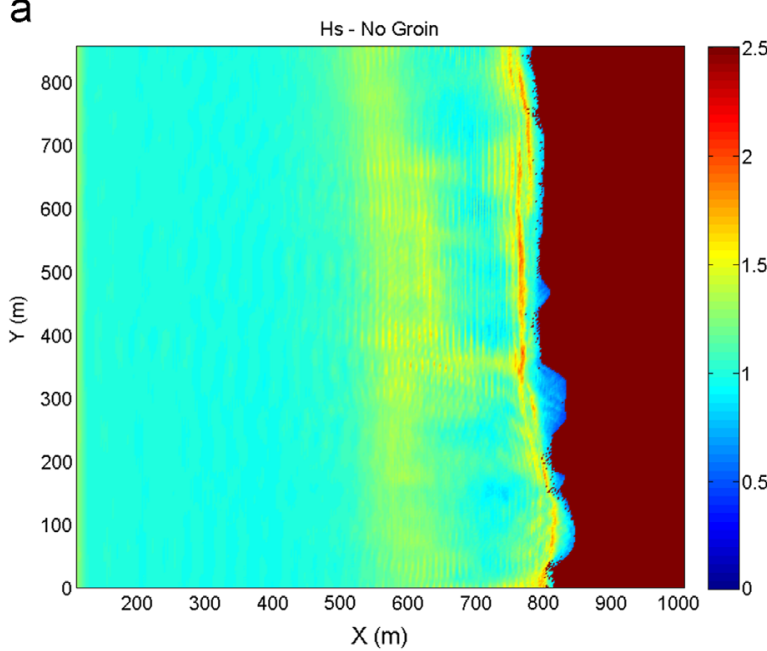

C

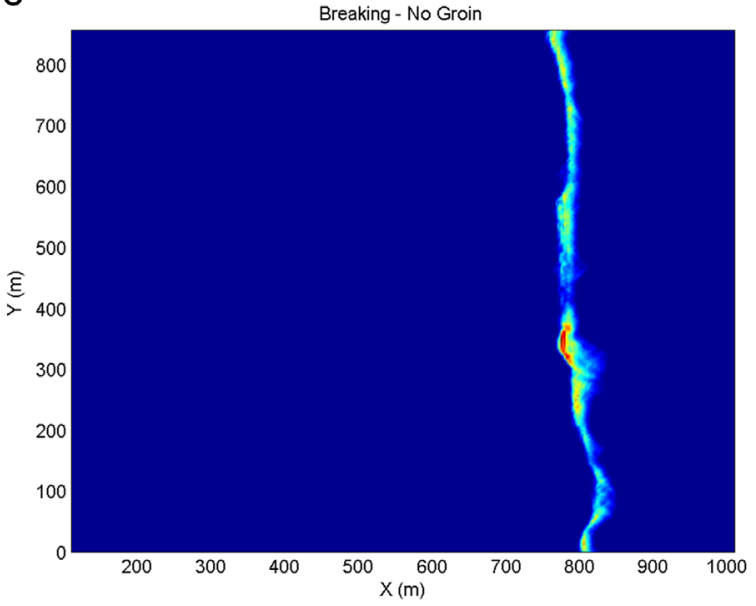

b

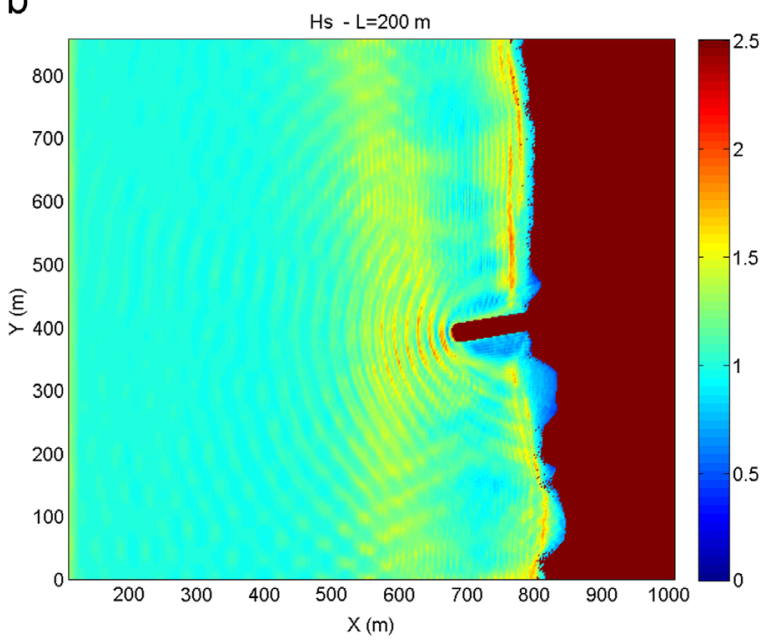

d

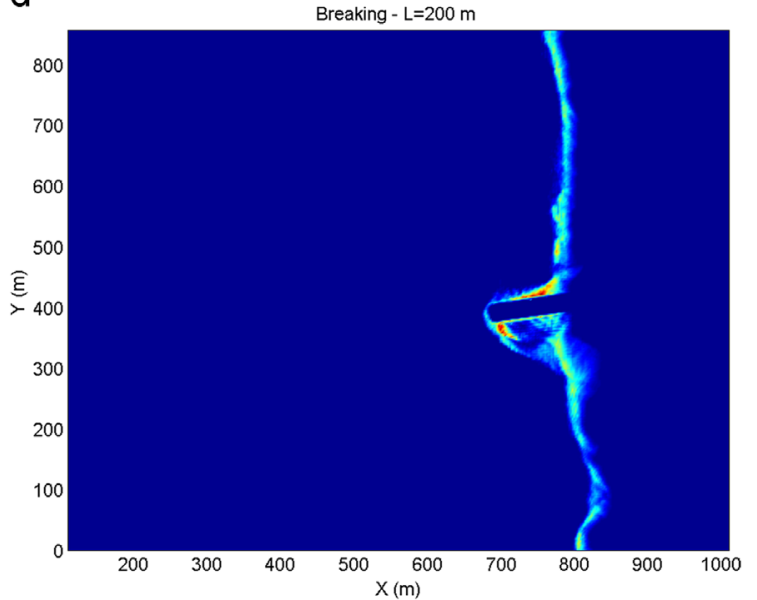

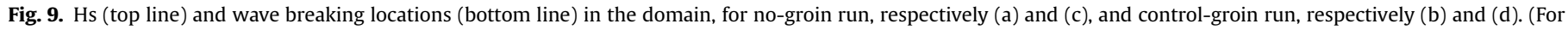
interpretation of the references to color in this figure legend, the reader is referred to the web version of this article.)

groin also changes this aspect, particularly by inducing more breaking events and phenomena such as diffraction and reflection, which justifies the significant differences in the $V$ component of velocity that spread to almost the entire domain.

\subsection{Other scenarios}

After analyzing the change of $\mathrm{Hs}$ and horizontal velocity imparted by a single $200 \mathrm{~m}$-long groin, with a $10^{\circ}$ orientation, considering an incident wave with $1.0 \mathrm{~m}$, and a sea-surface level of $0.50 \mathrm{~m}$, this study proceeds to the investigation of the different impacts that a groin would have, if its geometry was altered, or hydrodynamic conditions were different. All the new scenarios are compared to control-groin scenario, henceforward considered the control run, and the parameters not being changed were set to the same values as for the control run.

\subsubsection{Different groin length}

To evaluate the impact of changing groin length, three new groin lengths of $L=250 \mathrm{~m}, L=300 \mathrm{~m}$ and $L=400 \mathrm{~m}$ were studied. The percentual relative Hs differences between each run and the control run were considered significant when greater than $7.5 \%$, since no differences greater than $10 \%$ were observed.

As the length of the groin increases, the impact on the significant wave height extends further in the domain, and reflection phenomena due to the reflective upper and lower boundaries of the domain appear to become more significant. Depicted in Fig. 14, breaking events, in the control run mostly concentrated near the head of the groin, for longer groins, are shown to extend further to both sides of the head, and towards the shoreline in the lee-side of the groin. In the case of the $400 \mathrm{~m}$-long groin, breaking events start closer to the shore than the groin tip. The shadow-zone on the leeside also gets wider, with lower wave heights.

Fig. 15 shows that significant differences between each scenario and the control scenario become more wide-spread over the domain, although the dominance of the influence in the closest vicinity of the groin remains. For the $L=400 \mathrm{~m}$ groin, these differences extend as far as the left boundary of the domain.

A general tendency of increasing impact length and mean change follows the increasing of groin length, as well as a slight shift of this impact further to the lee-side of the groin. Although no solid conclusions can be drawn on the importance of the bar and trough positions, results might point to the importance of these features on the impact different groins can have on Hs.

\subsubsection{Different groin orientation}

After analyzing the impact of varying the length of the groin, the impact of changing groin orientation is explored. Hence, three groin orientations, $\phi=15^{\circ}, \phi=25^{\circ}$ and $\phi=30^{\circ}$ were chosen. Percentual relative Hs differences between each run and the control run were 
a

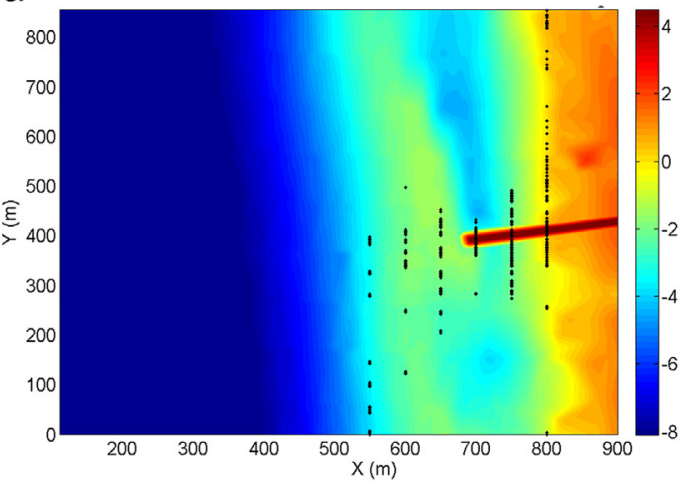

C

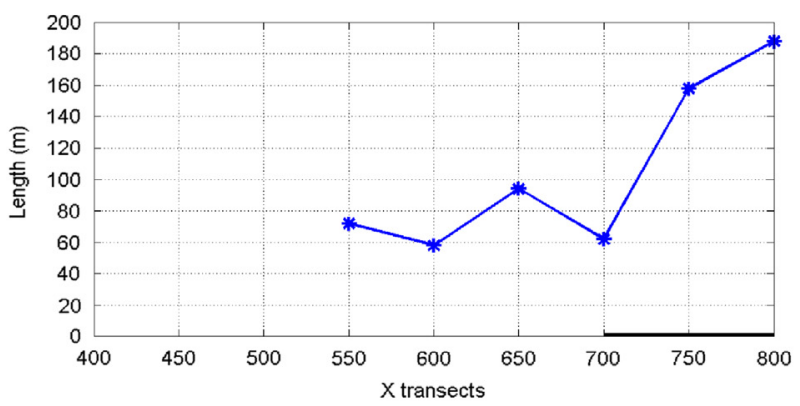

e

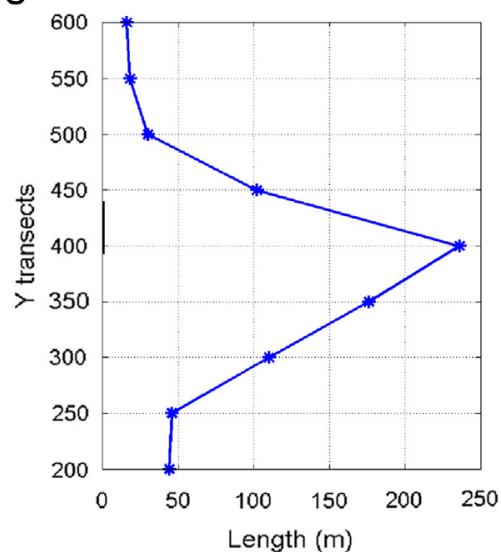

b

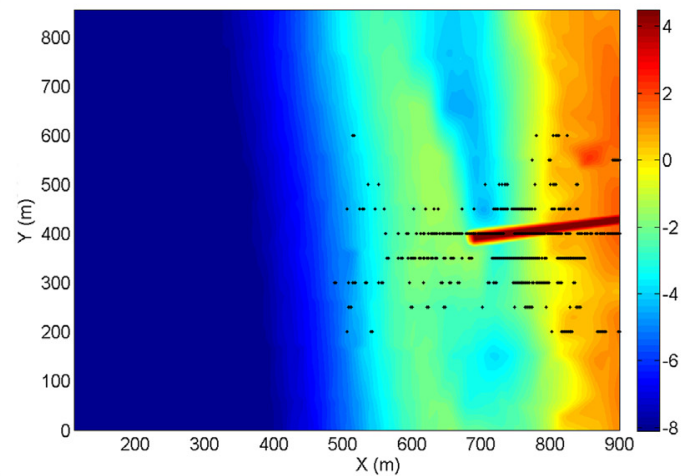

d

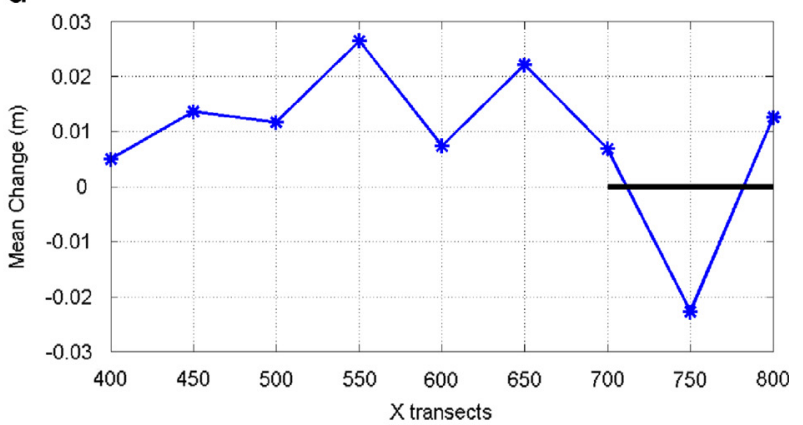

f

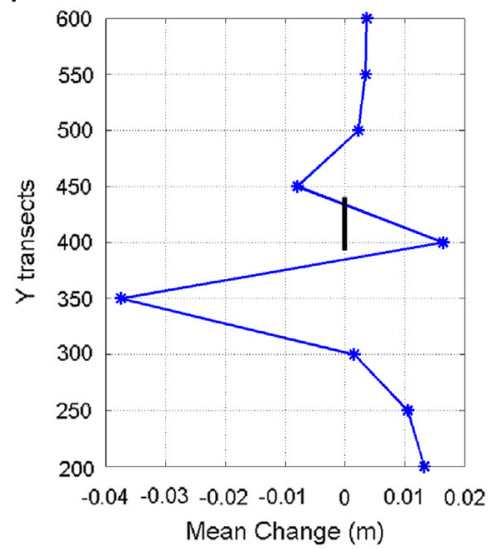

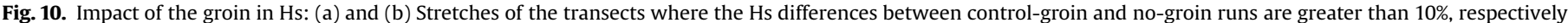

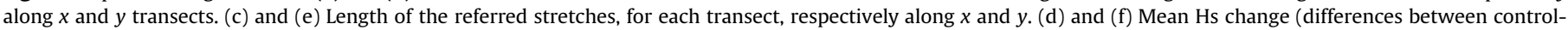
groin and no-groin runs), for each transect, respectively along $x$ and $y$.

considered significant when greater than $5 \%$, since no differences greater than $10 \%$ or $7.5 \%$ were observed.

As the angle increases, the shadow-zone in the lee-side of the groin also increases. For $\phi=15^{\circ}$, breaking still occurs mostly around the head of the groin, as in the control run. However, when $\phi$ suffers a $10^{\circ}$ increase, breaking starts taking place mostly against the updrift side-slope of the groin, which will tend to increase reflection of the incident waves, that arrive roughly perpendicularly to the shoreline (Fig. 16).

Changing groin orientation implies changes in the extension (towards offshore) of the groin, the wave breaking locations and in phenomena such as diffraction and reflection. Hence, it becomes difficult to evaluate the specific impact of changing just the orientation (Fig. 17).

The relative difference between orientations is hard to interpret, since, and contrariwise to the changing of the other studied parameters, the differences between the control run and the three chosen scenarios do not seem to follow any specific and predictable pattern.
Although for $\phi=15^{\circ}$ the length of groin impact along the transects is apparently longer than for greater values of $\phi$ (most likely because the groin extends further offshore in this case), the greatest values of mean change happen for $\phi=25^{\circ}$ and $\phi=30^{\circ}$ (possibly due to enhanced breaking or reflection and diffraction effects).

From the three scenarios chosen to evaluate the impact of groin orientation, the only conclusions that can be solidly drawn, is that the impact of changing groin orientation has a minor significance (no significant differences above $10 \%$ or $7.5 \%$ were observed) and that more scenarios would be necessary in order to better understand the effects of changing this specific parameter.

\subsubsection{Different significant incident-wave height}

In addition to groin configuration, also the incident wave conditions are an important factor to account for when evaluating groin impact on significant wave height. Hence, to understand the influence of the significant height of the incident waves, three 
a

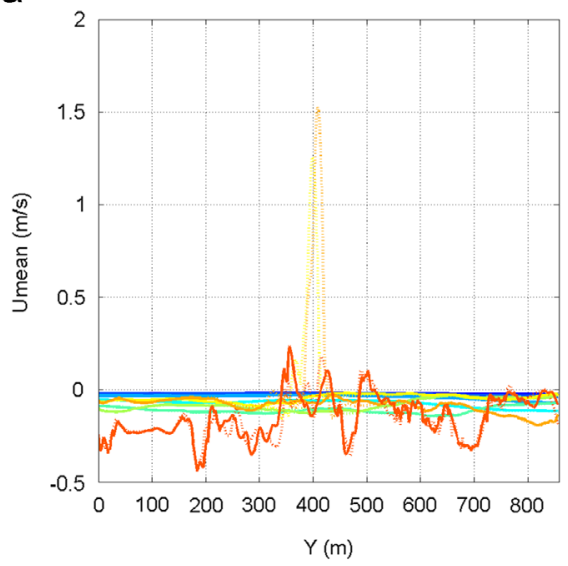

C

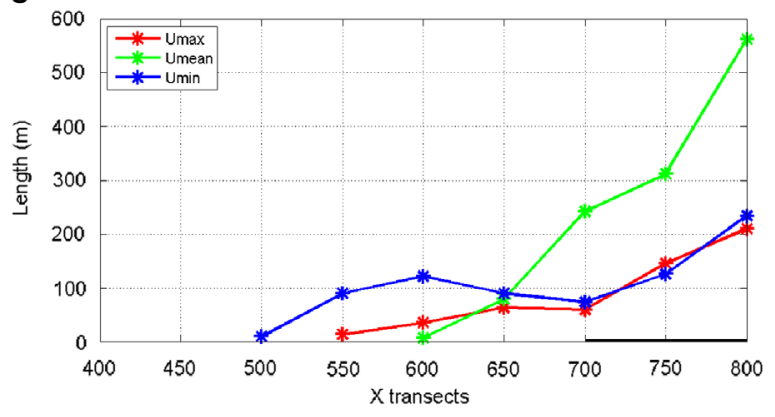

e
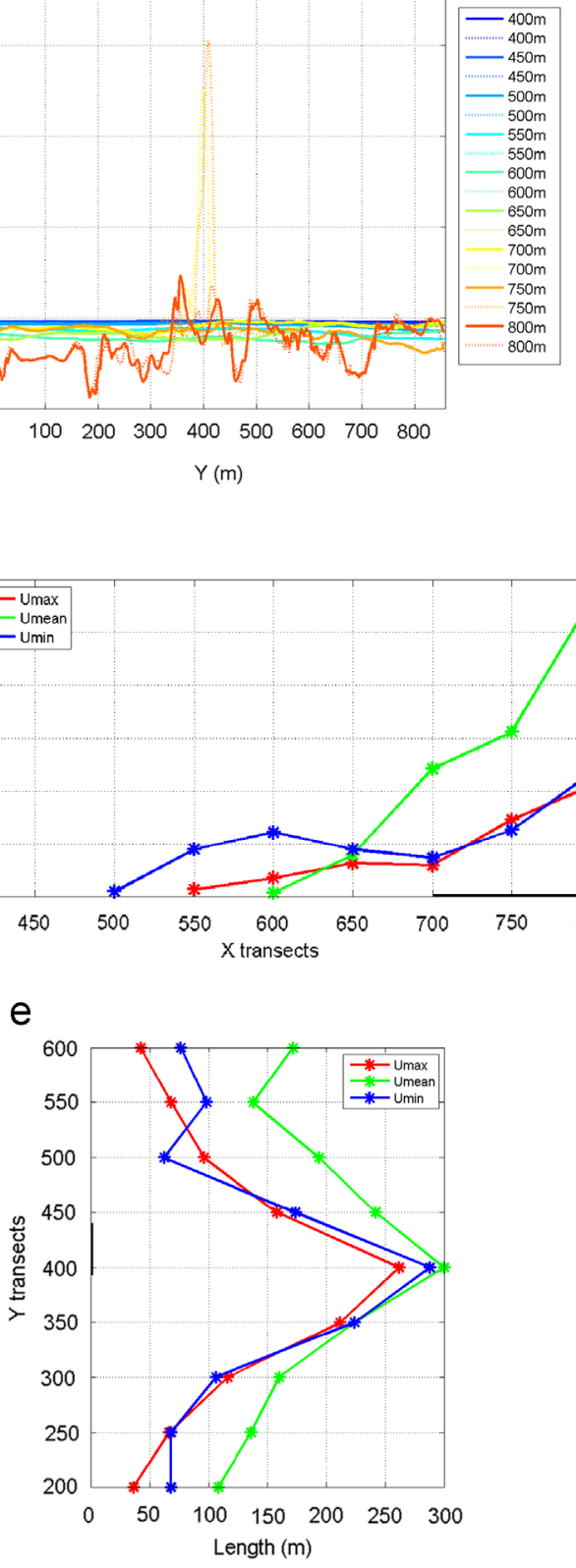

b

d

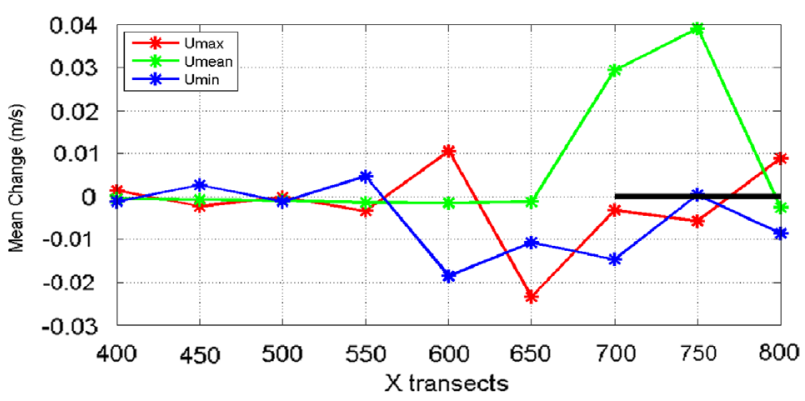

$f$

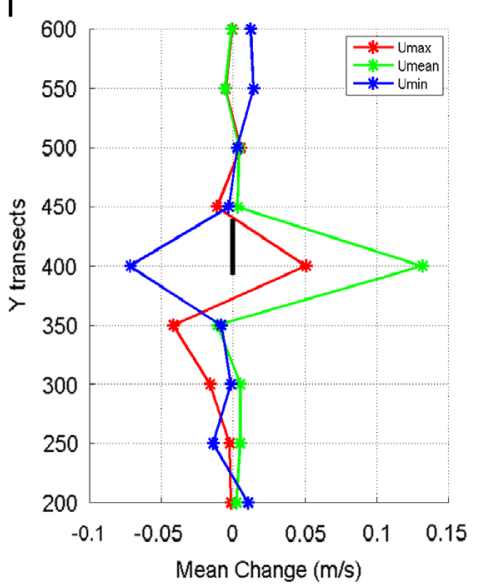

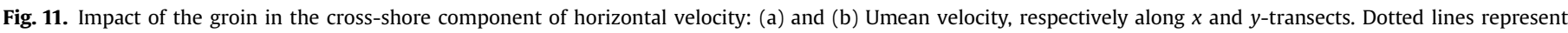

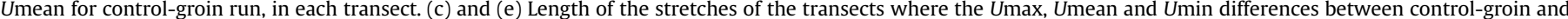

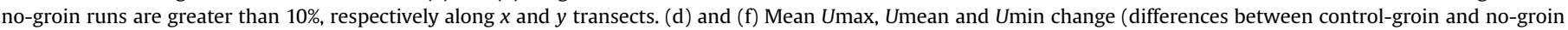
runs), for each transect, respectively along $x$ and $y$.

different incident significant wave heights were chosen: $H s=1.5 \mathrm{~m}, H s=2.0 \mathrm{~m}$ and $H s=3.0 \mathrm{~m}$. The relative Hs differences between each run and the control run were considered significant when greater than $10 \%$.

Incident wave height change has an obvious effect on wave height in the domain, which increases concomitantly with significant incident-wave height increase. In the transects closer to the shore, the Hs increase is attenuated by the groin.

\subsubsection{Different sea-surface level}

The last of the parameters to be considered is sea-surface level (which is supposed to relate to a static tide level). The relative percentual Hs differences between each run and the control run were considered significant when greater than $10 \%$.

The fact that the significant incident-wave height imposed in all three scenarios of Figs. 18 and 19 is $1.0 \mathrm{~m}$, implies that breaking will always occur closer to shore than the head of the groin. However, it is still possible to observe that, for lower SSL, the breaking zone occurs closer to the head of the groin, and shifts towards closer to shore as SSL rises. When SSL is higher (1.50 and $2.40 \mathrm{~m}$ ), the wave breaking line, also denounced by the greatest Hs region of the domain, is pushed further away from the shoreline (over $100 \mathrm{~m}$, in some places) and extends wider in the cross-shore direction than when SSL is lower.

The greatest lengths, with an exception for the two transects closer to the shore, are calculated for the transects that follow the 
a

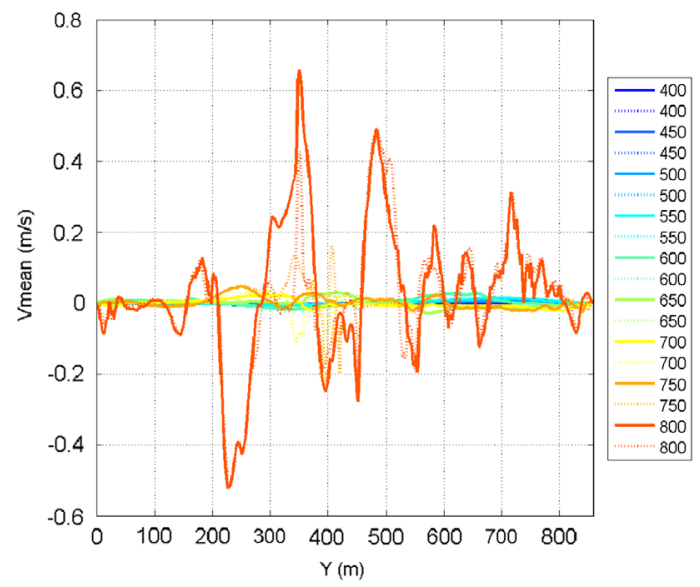

C

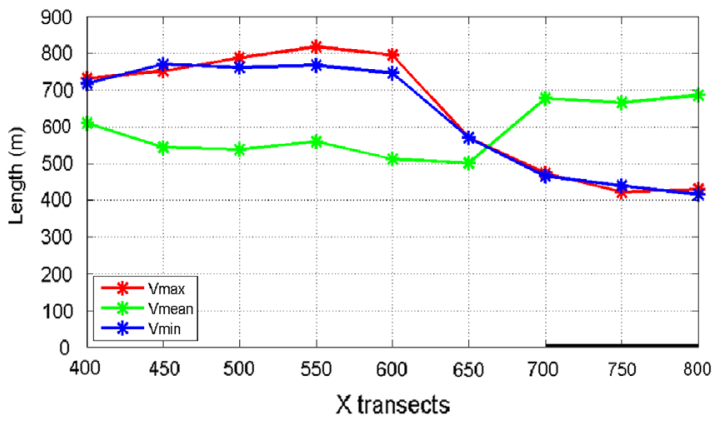

e

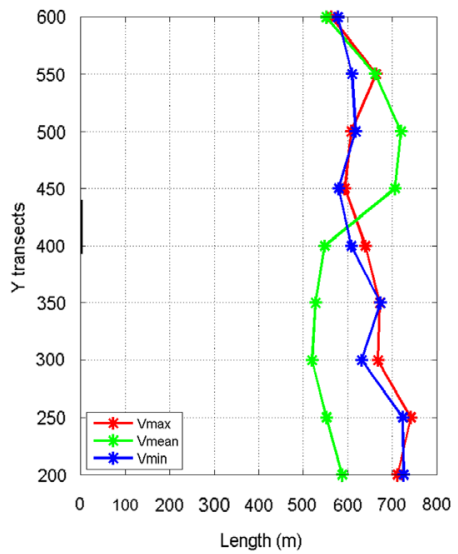

b

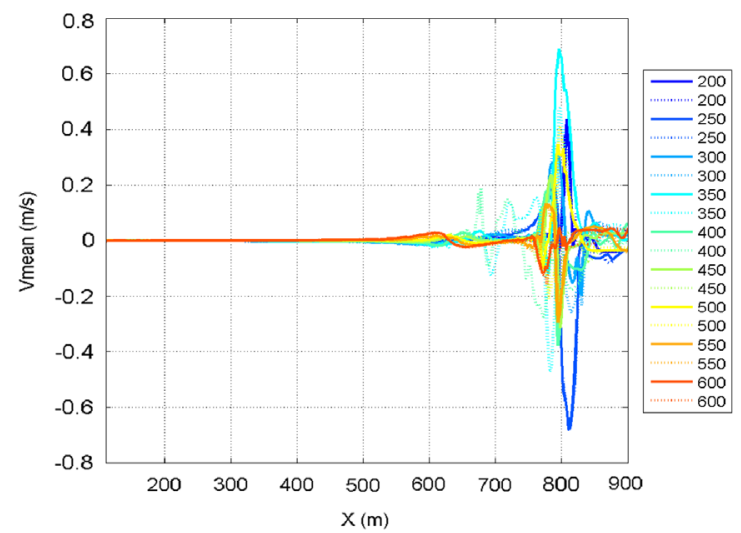

d

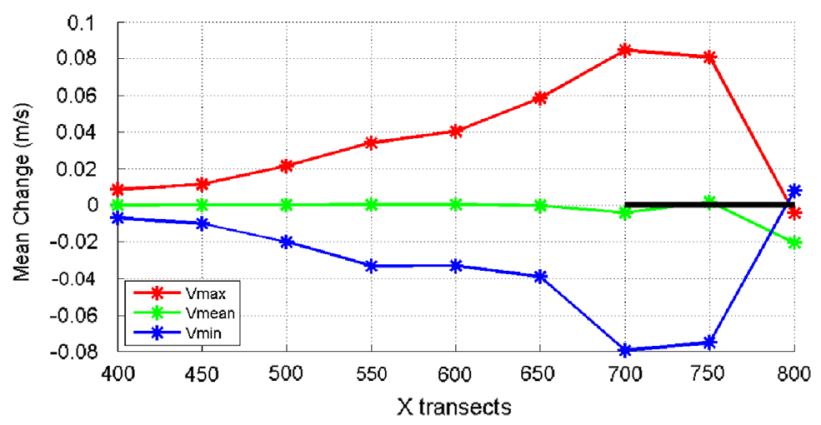

f

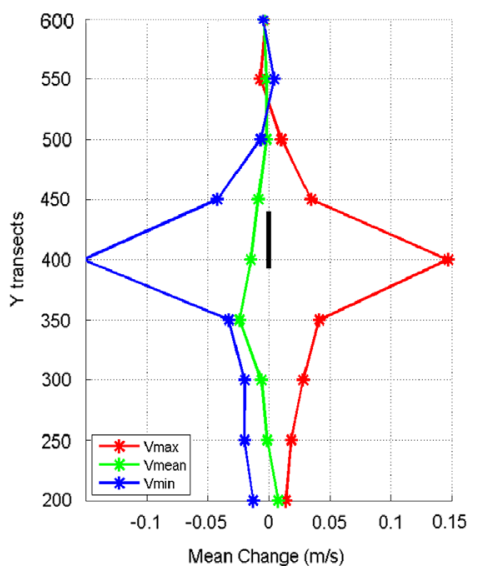

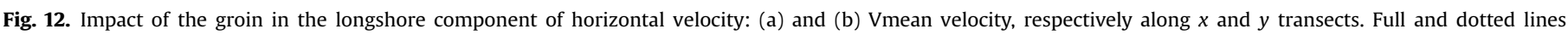

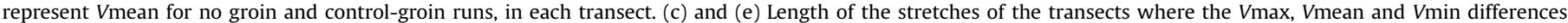

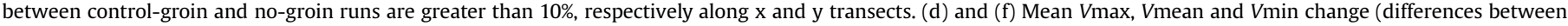
control-groin and no-groin runs), for each transect, respectively along $x$ and $y$.

shallower depths of the submerged bar (Fig. 20). The two exception transects are located very close to, and even over the shoreline, and hence SSL has a stronger immediate impact, since it conditions the position of the shoreline itself. The influence of the groin is also evident in its vicinity, particularly along $y$-transects, where significant differences cover greater stretches in the transects that cross the groin and are closer to it.

The mean change is related to the differences in every grid point of the transect between each SSL scenario and the control run, and so the presence of bathymetric features, such as the submerged bar and trough, affect each $y$-transect differently, which may justify the differences of mean change between consecutive transects.

\subsubsection{Total impact of the four studied parameters}

In order to better understand the relative impact of each of the four studied parameters, a comparative analysis is now presented. This impact is considered as the total length of every stretch of each transect, along $x$ - and $y$-directions (respectively, Fig. 21a and b), where percentual relative differences of $\mathrm{Hs}$ between each scenario and the control run are greater than a threshold value, which varies accordingly to the parameter considered. The minimum-possible total length is zero for both $x$ - and $y$-transects and the maximumpossible total length is $7722 \mathrm{~m}$, for $x$-transects, and $8100 \mathrm{~m}$ for $y$ transects, both representing a sum of the length of all the nine transects in each direction, respectively. 
a

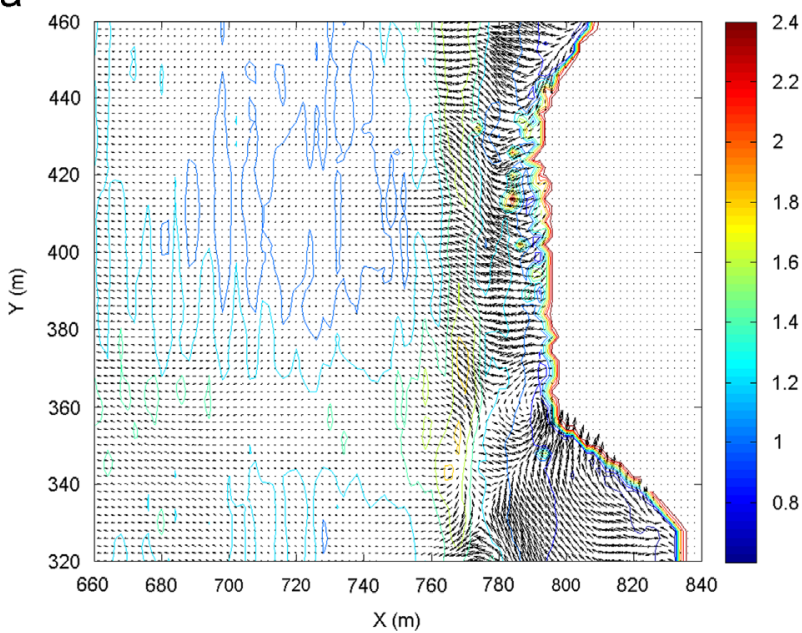

b

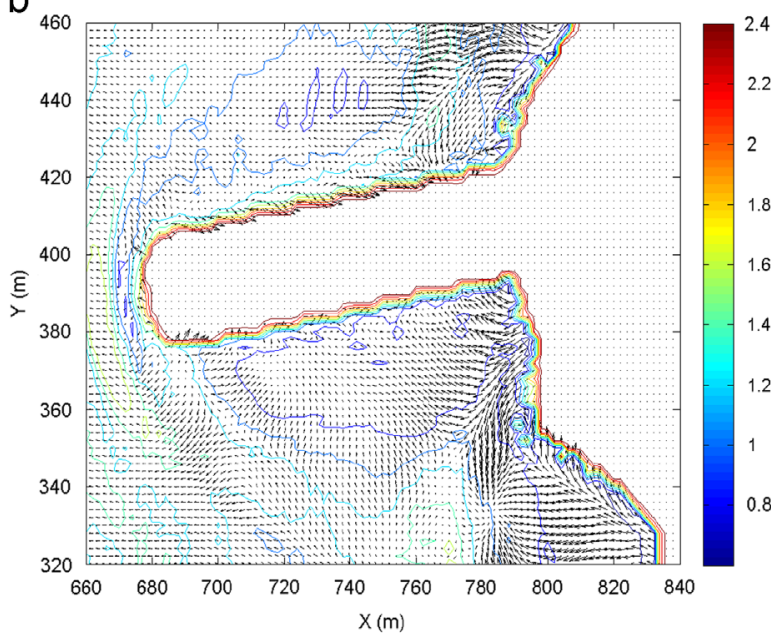

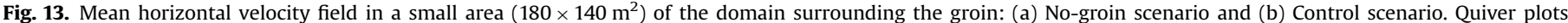

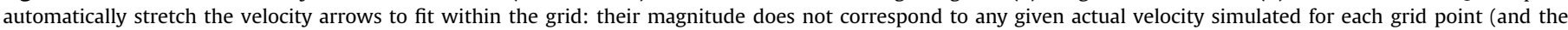

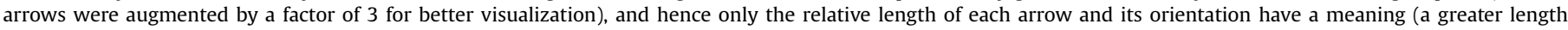
represents a greater velocity, and the vector represents the direction of simulated velocity). Color contours represent Hs (m).

a

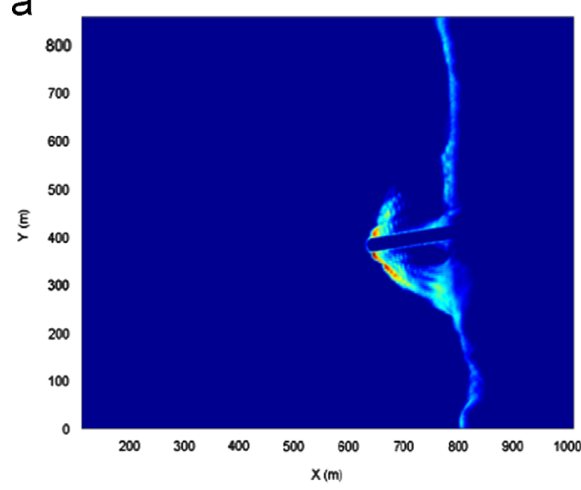

b

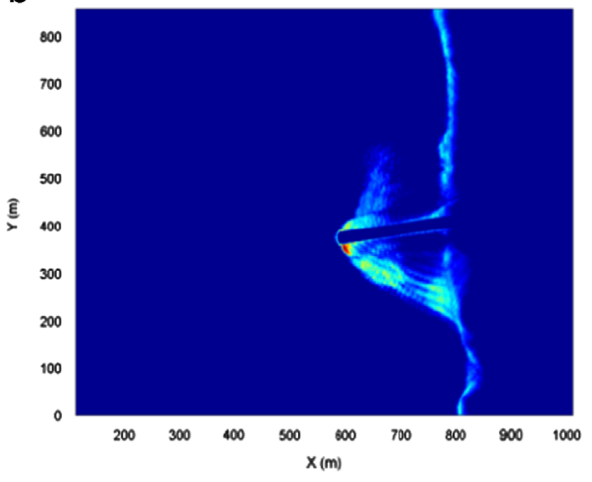

C

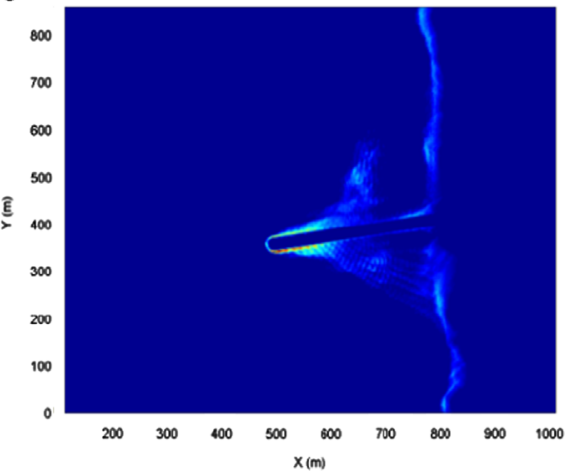

Fig. 14. Wave breaking locations in the domain, for (a) $L=250 \mathrm{~m}$, (b) $L=300 \mathrm{~m}$ and (c) $L=400 \mathrm{~m}$.

The purpose of Fig. 21 plots is to offer a qualitative comparative analysis of the impact of each parameter, than the actual absolute values of impact length. The numbers on the $x$-axis are merely indicative of the different scenarios.

Firstly, it should be remembered that both incident Hs and SSL impacts were calculated accounting for significant percentual relative differences of $10 \%, \mathrm{~L}$ impact was only relevant when differences were greater than $7.5 \%$ and $\phi$ determined the need of setting the lower limit of significant differences to $5 \%$. Therefore, the environment factors, $\mathrm{Hs}$ and SSL, are significantly more important to correctly assess groin impact on the nearshore hydrodynamics, followed by groin length and its orientation last.

The total length of the impact of changing the incident significant wave height is much greater than the impact of changing any of the other parameters and is more notorious along the $x$-transects (longshore direction) than along the $y$-transects (crossshore direction).

From Fig. 21 it would appear that changing SSL results in a shorter length of groin impact than changing $L$ or $\phi$, but it is important to remember that the threshold for significant differences considered for SSL was greater than for those two parameters. Hence, SSL can be considered to have a significantly less important impact on significant wave height in the domain than the $H s$ parameter, but greater than $L$ and $\phi$. Furthermore, impact of changing sea-surface level is both globally and between scenarios greater in the longshore direction than its impact in the cross-shore direction.
Although less important than environmental conditions, groin characteristics also have their share of impact on significant wave height in the domain. Firstly, and following a quite linear and similar trend in both $x$ - and $y$-directions, the length of the groin has the greater impact, with differences becoming significant over the $7.5 \%$ threshold. The parameter that appears to have the smaller impact on significant wave height is the orientation of the groin. The response of Hs to the variation of $\phi$ is difficult to unravel, as it follows no apparent trend, and several factors that respond to changing orientation might be influencing that response. In the longshore direction, increasing $\phi$ seems to result in a lesser impact, whereas in the cross-shore direction an irregular trend is found between scenarios. More scenarios are due to be considered in order to better understand this particular impact.

\section{Conclusions and future improvements}

The impact on significant wave height and horizontal velocity in the specific site, after adding a groin to the original domain bathymetry was analyzed, and several scenarios, with different groin lengths and orientations and different incident significant wave heights and sea-surface levels were explored and some conclusions can be drawn.

Firstly, it is expected that building a groin in a beach will lead to changes in wave conditions and the horizontal velocity field 
a

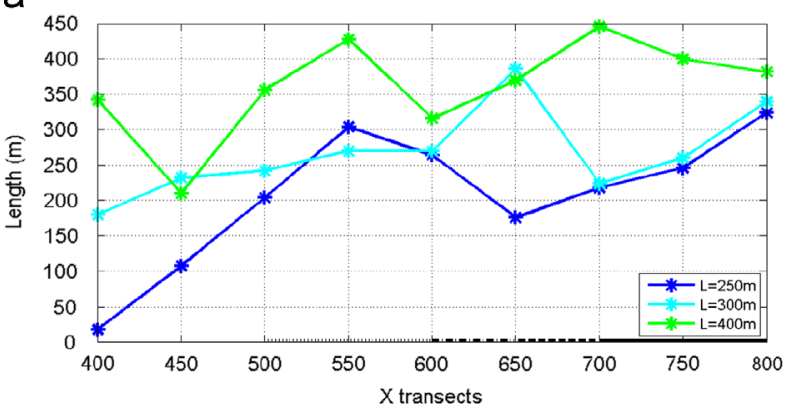

C

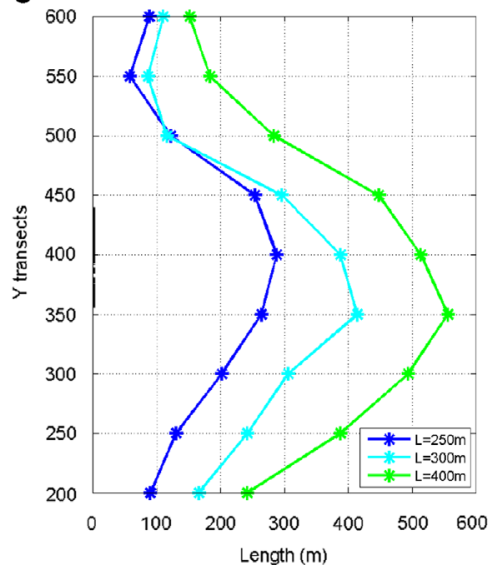

b

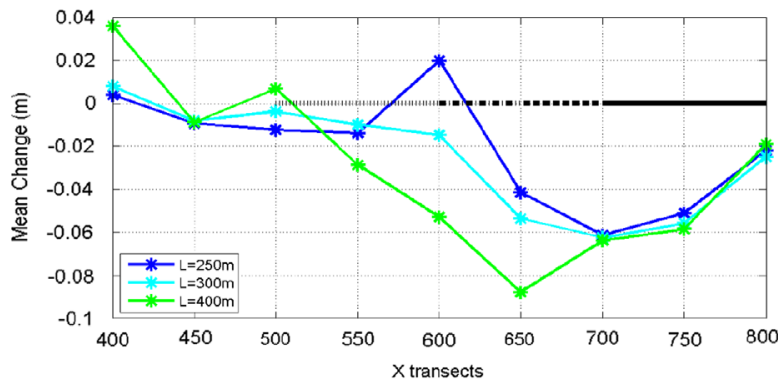

d

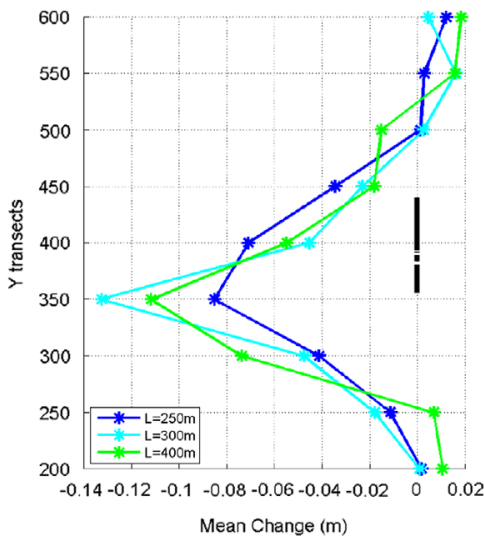

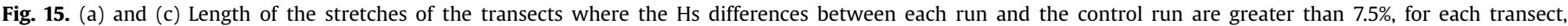
respectively along $x$ and $y$. (b) and (d) Mean change (m) (differences between each run and the control run), respectively along $x$ and $y$.

a

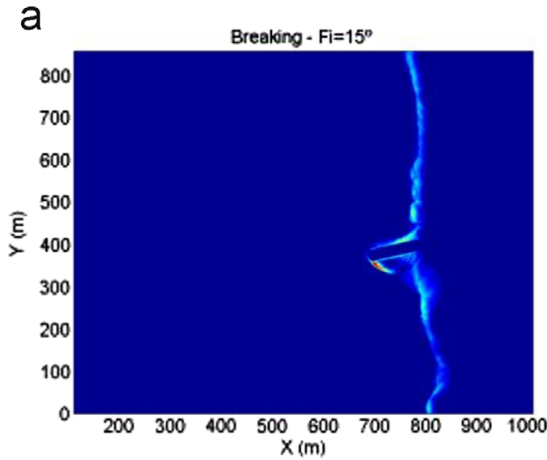

b

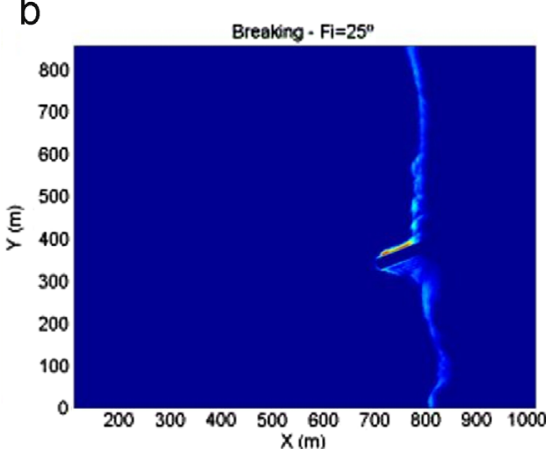

C

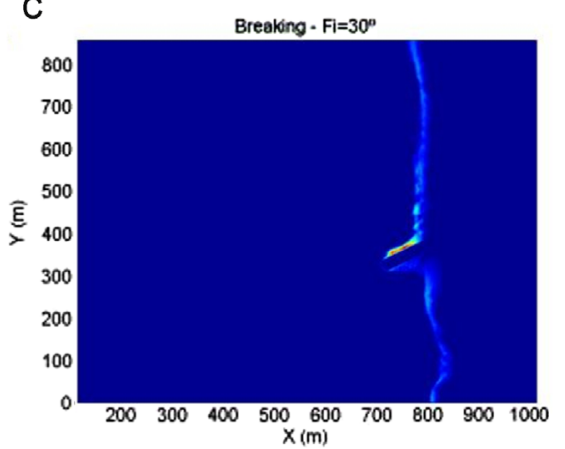

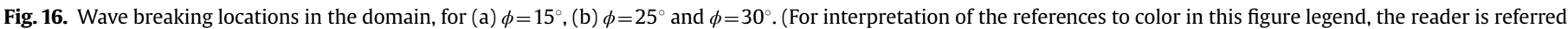
to the web version of this article.)

nearshore. Diffraction, refraction and reflection phenomena acquire a greater relevance in the domain and wave breaking locations tend to change. It should also be considered that the changes caused by the groin presence are specially felt on its lee-side and influence differently the nearshore region to each side of the groin.

The general tendency is of a significant wave height and velocity decrease in the longshore transects closer to shore than the head of the groin, particularly on its lee-side, where the shadow-zone has a sheltering effect on wave conditions. Contrariwise, in the closest vicinity of the groin tip, wave height tends to increase, together with velocity. The velocity tends to be directed towards the shore near breaking regions, and seawards away from these regions, since a weak undertow is the most relevant cross-shore velocity simulated by the model where no breaking is present.

The main conclusion of the present work is that the environmental factors, incident wave height, $\mathrm{Hs}$, and sea-surface level, SSL, are significantly more important to correctly assess groin impact on nearshore hydrodynamics, followed by the geometric factors, the length of the groin, $L$, and its orientation, $\phi$, at last. It is important to stress that this conclusion was obtained for one specific field site, with its very own and unique bathymetry, and that the extension of these findings to other cases is limited to very similar field sites. In order to broaden the scope of such conclusions, similar studies should be carried out considering a significant variety of field sites.

Hence, if a groin were to be built anywhere, firstly, the most common wave conditions should be considered, since the variation of significant incident-wave height imparts the greater changes in wave height nearshore, where the groin would be located. If the typical wave heights exceed a certain height, the groin effect might not be so important in wave breaking locations. Then, the typical tidal range should be evaluated, since a small $2 \mathrm{~m}$ 
a

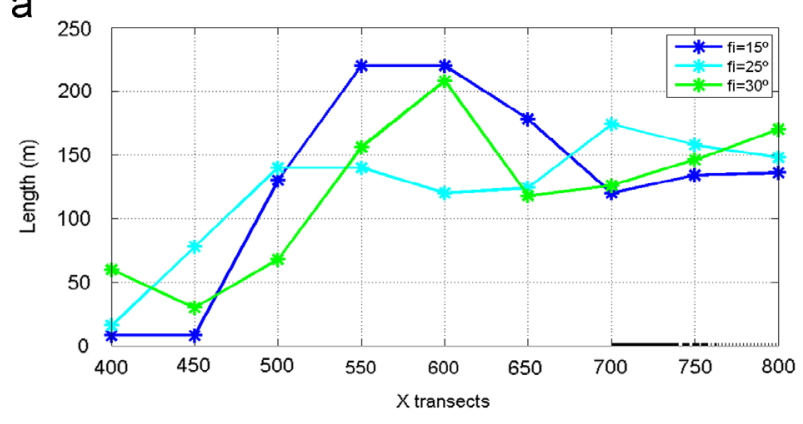

C

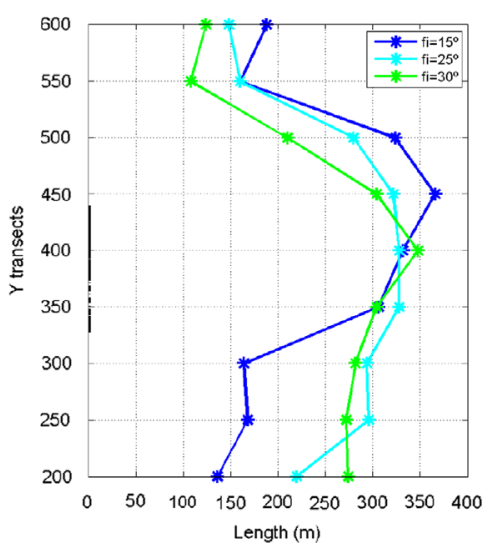

b

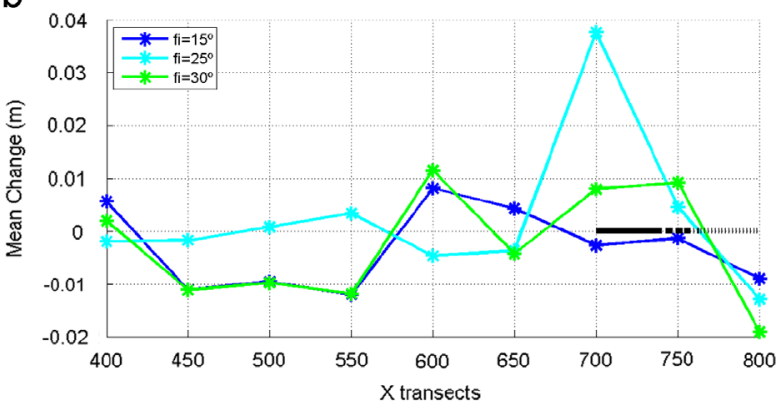

d

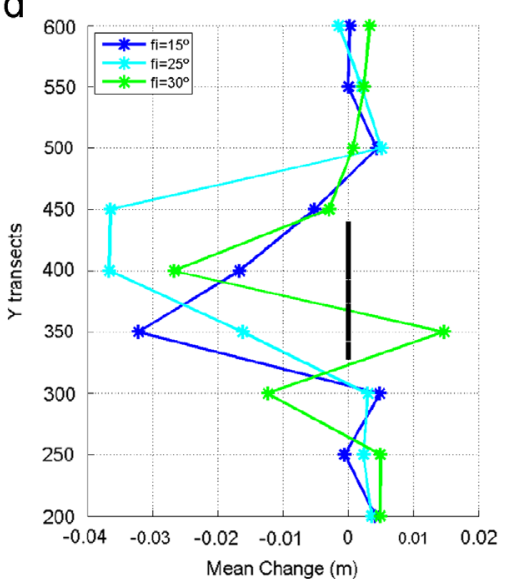

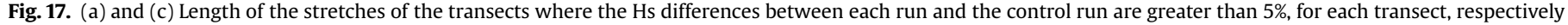
along $x$ and $y$. (b) and (d) Mean change (m) (differences between each run and the control run), respectively along $x$ and $y$.

a

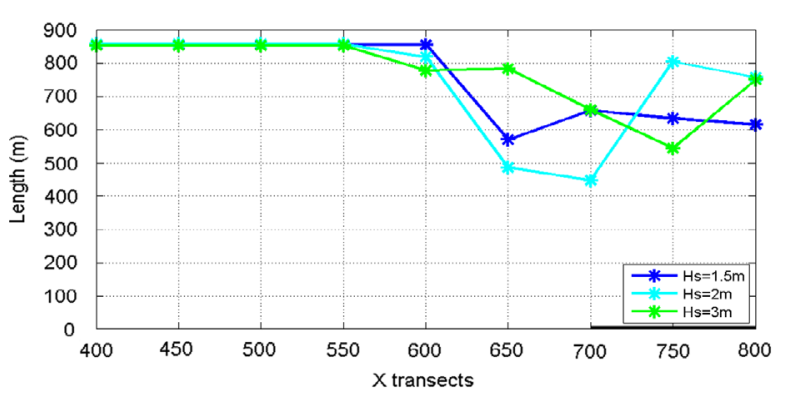

C

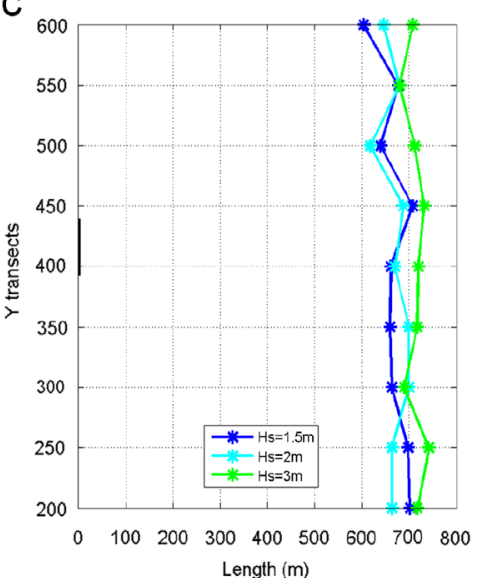

b

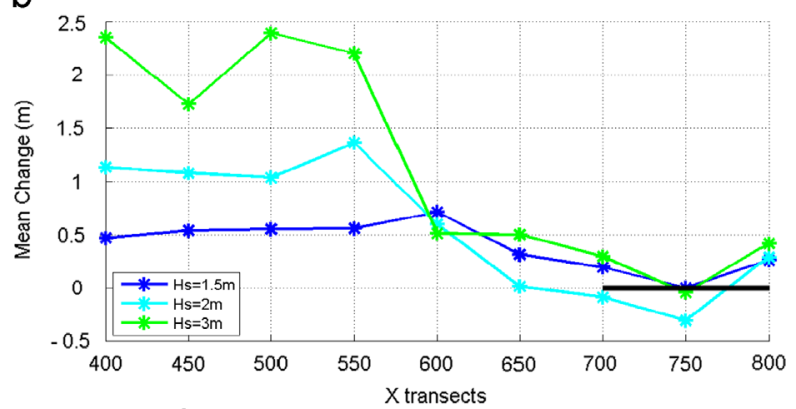

d

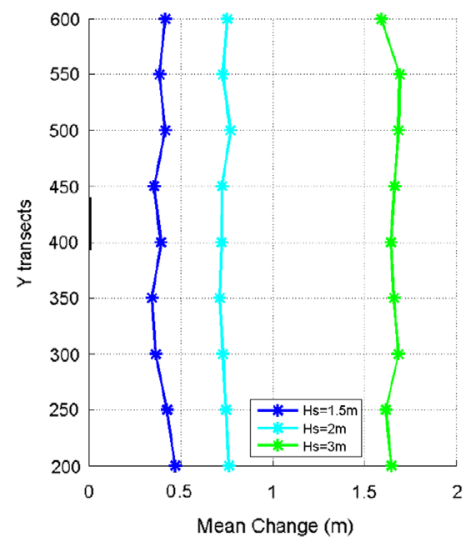

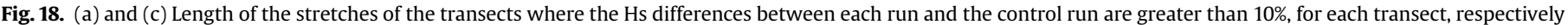
along $x$ and $y$. (b) and (d) Mean change (m) (differences between each run and the control run), respectively along $x$ and $y$. 
a

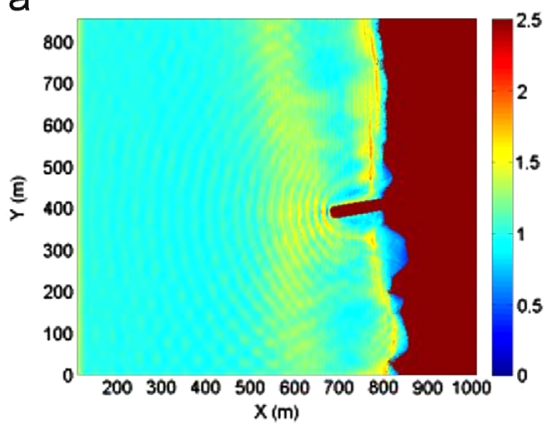

b

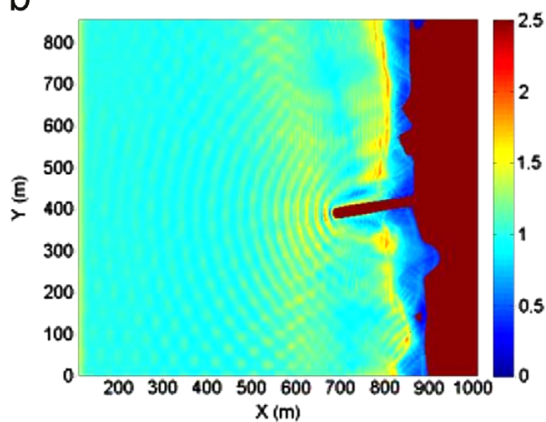

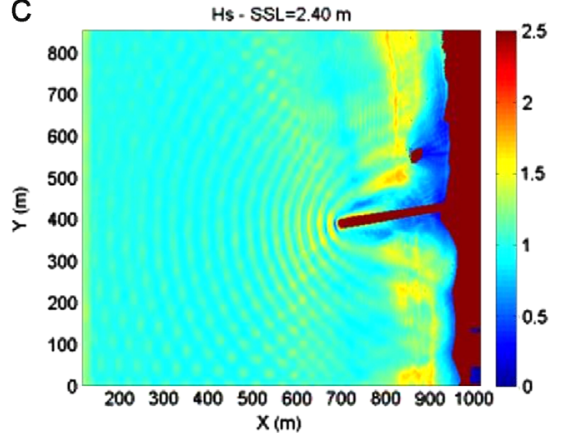

Fig. 19. Hs in the domain, for (a) $\mathrm{SSL}=0.75 \mathrm{~m}$, (b) $\mathrm{SSL}=1.50 \mathrm{~m}$ and (c) $\mathrm{SSL}=2.50 \mathrm{~m}$.

a

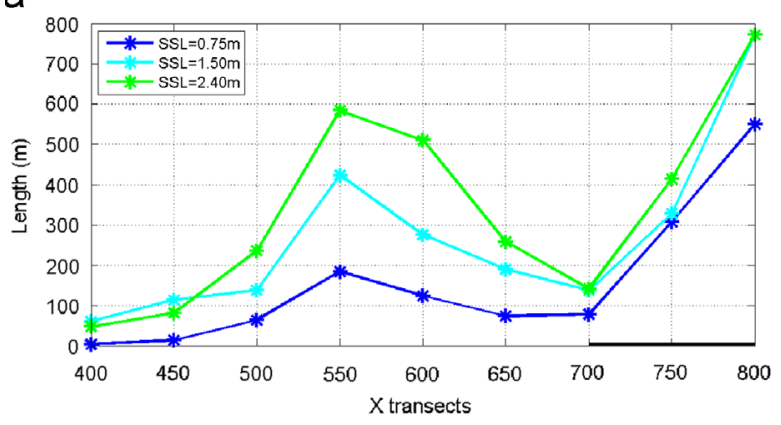

C

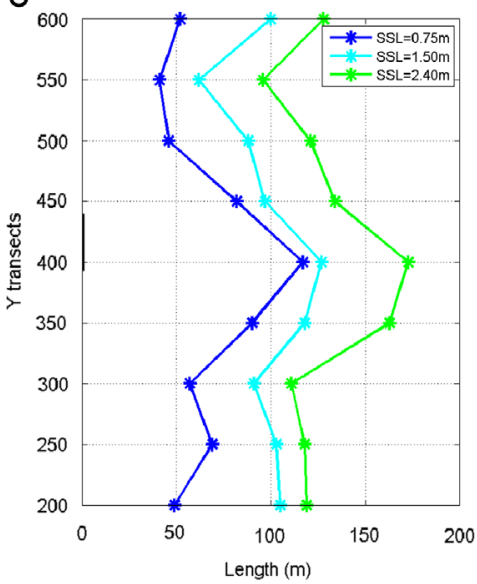

b

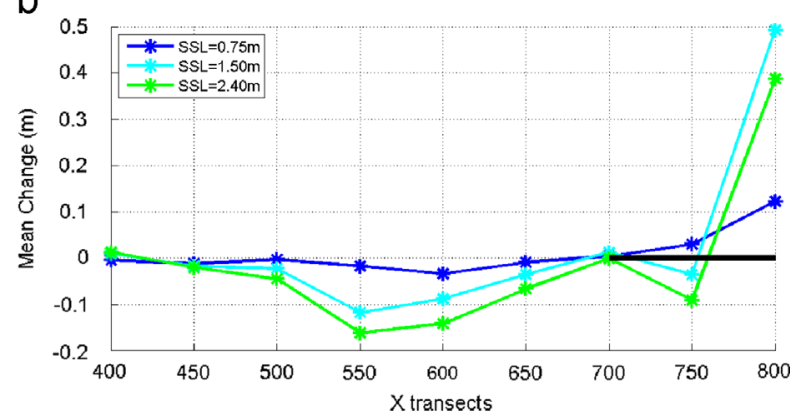

d

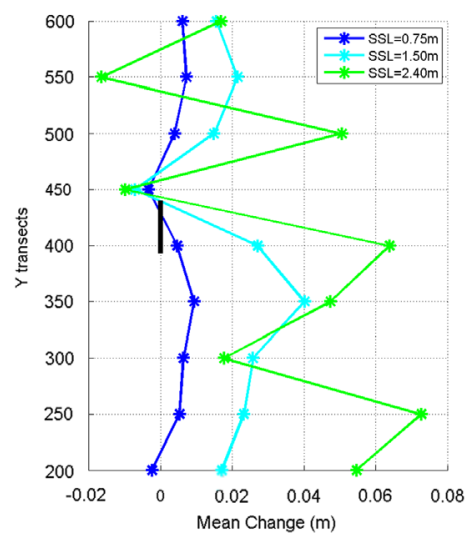

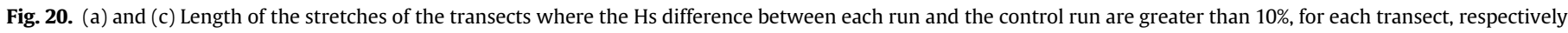
along $x$ and $y$. (b) and (d) Mean change (m) (differences between each run and the control run), respectively along $x$ and $y$.

change in sea-surface level can cause great depth changes over bathymetric features and thus influence wave propagation. Both these two environmental factors will have a severe influence on the wave breaking locations, which will then further condition wave height and horizontal velocities.

When the typical breaking locations for different wave conditions and sea-surface levels are studied, it is then important to define groin characteristics, in order to obtain the best results for shoreline protection. Different lengths are to be considered, seen that the greater the length, the greater the sheltering effect expected, and extending further to the lee-side of the groin. The impact will also reach a broader region of the domain. At last, with a smaller verified impact on wave conditions, the best orientation of the groin is hard to unravel. Since it influences other factors, such as groin extension towards offshore, and reflection and diffraction phenomena, it becomes difficult to correctly assess the impacts of changing groin orientation, and results show an apparently almost- random behavior. More groin orientations should be considered for a better understanding of the influence of this parameter.

Hereupon, future improvements could help overcoming some of the current limitations of this work. When the differences between each scenario and the control run were calculated, an absolute value was assumed, and thus the relation of those differences with increasing or decreasing Hs was not considered, and only the change of Hs was analyzed, without specifically being scrutinized if that change was either positive (Hs increase) or negative (Hs decrease). Carrying this analysis further could help understand the origin of such changes in each region of the domain.

Moreover, the study of groin impact for different scenarios was only done for $\mathrm{Hs}$, and the investigation of groin impact in the horizontal velocity field in each scenario would also be an important improvement to this work.

Also, the results obtained for this specific site should be compared with those of other field sites, for evaluation of the 
a

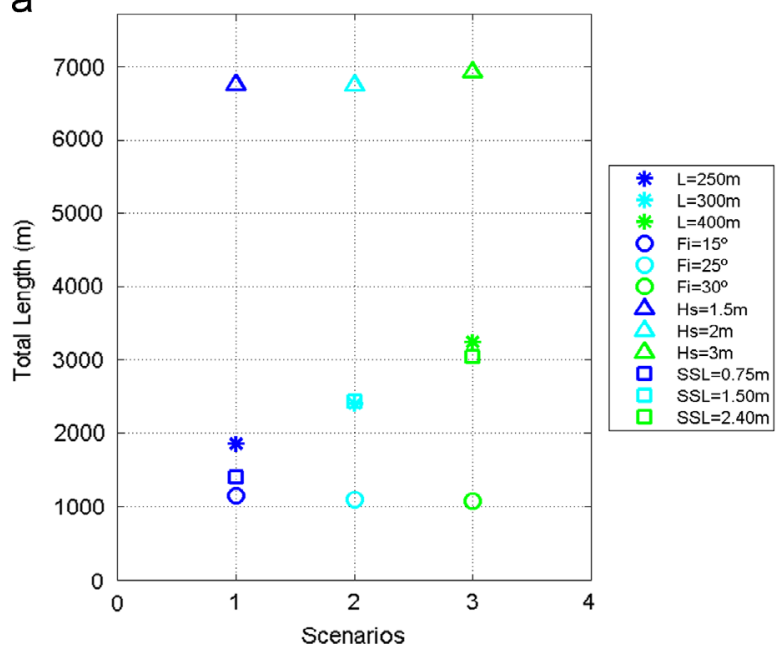

b

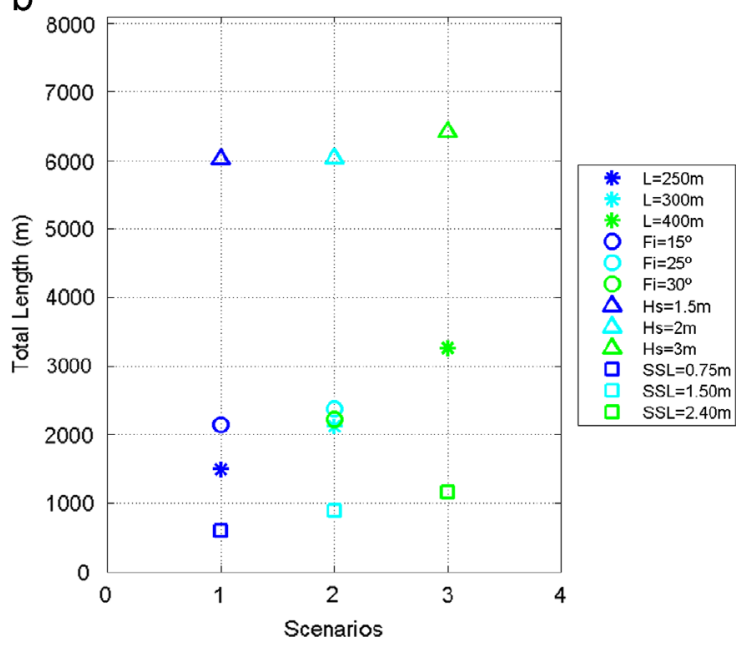

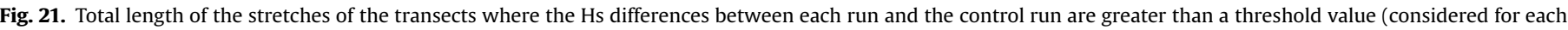
parameter) for each transect, respectively along (a) $x$ and (b) $y$ directions.

importance of bathymetry in a more general characterization of groin impact, since it presents important site-specific characteristics, such as beach forms and bars, cross-shore profile and slope, that can significantly change wave propagation due to induced refraction and shoaling effects, limiting a broader approach and interpretation of the results, when only a single field site is evaluated.

Finally, the greatest further improvement for this research would be carrying through the analysis of the changes of Hs and horizontal velocities under different scenarios to evaluate alterations in the sediment transport nearshore, and then model shoreline change in different situations.

\section{Acknowledgments}

This work was carried out in the scope of BRISA project BReaking waves and Induced SAnd transport (PTDC/ECM/67411/ 2006), funded by the FCT (Science and Technology Foundation, Portugal)

\section{References}

Engineers, U. A. C. o. 1992. Coastal groins and nearshore breakwaters. Engineering and Design. Washington, DC, Department of the Army, US Army Corps of Engineers. Engineering Manual 1110-2-1617, pp. 91.

Basco, D.R., 2006. Shore Protection Projects. Coastal Engineering Manual. Washington, DC, U.S. Army Corps of Engineers. Part V-Coastal Project Planning and Design, pp. 59-76.

Basco, D.R., Pope, J., 2004. Groin functional design guidance from the coastal engineering manual. J. Coastal Res. (33), 121-130.
Bezerra, M., Ferreira, O., 2010. Relatório de campo - Universidade do Algarve. Projecto BRISA - Campanha da Costa da Caparica (Praia da Saúde) (11 a 15 de Maio de 2010).

Bowen, A.J., Inman, D.L., 1969. Rip currents 2. Laboratory and field observations. J. Geophys. Res.-Oceans 74 (23), 5479-5490.

Chen, Q., Kirby, J.T., Dalrymple, R.A., Kennedy, A.B., Chawla, A., 2000. Boussines Modeling of Wave Transformation, Breaking, and Runup. II: 2D. J. Waterway, Port, Coastal Ocean Eng., 126; 48-56.

Dean, R.G., 1978. Coastal structures and their interaction with the shoreline Application of Stochastic Processes in Sediment Transport. In: Kikkaua, H.W.S. A.H. (Ed.), Water Resources Publications, Littleton, CO.

Hansen, J., Svendsen, I., 1979. Regular Waves in Shoaling Water: Experimental Data Technical Report. ISVA Series, Paper 21.

Hanson, H., Larson, M., 2004. Wave directional characteristics as a design parameter for groin performance. J. Coastal Res. (33F), 121-130.

Kennedy, A., Chen, Q., Kirby, J., Dalrymple, R., 2000. Boussinesq modeling of wave transformation, breaking, and runup. Part I: 1D. J.Waterway, Port, Coastal Ocean Eng. 126 (1), 39-47.

Kirby, J., Wei, G., Chen, Q., Kennedy, A., Dalrymple, R., 1998. FUNWAVE 1.0: Fully Nonlinear Boussinesq Wave Model Documentation and User's Manual. Center for Applied EngiCoastal Research, University of Delaware.

Lynnet, P., Liu, P., 2002. Modeling wave generation, evolution and interaction with depth-integrated, dispersive wave equations. Cornell University Long and Intermediate Wave Modeling Package.

Lynnet, P., Liu, P., 2004. Modeling Wave Generation, Evolution and Interaction with Depth-Integrated Dispersive Wave Equations, Cornell University Long and Intermediate Wave Modeling Package.

Nwogu, O., 1993. Alternative form of Boussinesq equations for nearshore wave propagation. J. Waterway, Port, Coastal .Ocean Eng. 119 (6), 618-638.

Pattiaratchi, C., Olsson, D., Hetzel, Y., Lowe, R., 2009. Wave-driven circulation patterns in the lee of groynes. Continental Shelf Res. 29, 1961-1974.

Rocha, M.V.L., 2011. Numerical Modeling of Groin Impact on Nearshore Hydrodynamics. M.Sc., Physics Department, Universidade de Aveiro.

Silvester, R., Hsu, J.R.C., 1993. Coastal Stabilization: Innovative Concepts. PTR Prentice-Hall, Englewood Cliffs, NJ.

Wei, G., Kirby, J., 1995. A time-dependent numerical code for extended Boussines equations. J. Waterway, Port, Coastal .Ocean Eng. 120, 251-261.

Wei, G., Kirby, J.T., Grilli, S.T., Subramanya, R., 1995. A fully nonlinear Boussines model for surface waves. Part 1 . Highly nonlinear unsteady waves. J. Fluid Mech. 294, 71-92. 